Puede citar este artículo como:

Igual Luis, David. «¿Los mercaderes son egualadors del món? autóctonos y extranjeros en el comercio bajomedieval de Valencia». Anales de la Universidad de Alicante. Historia Medieval, N. 18 (2012-2014): 119-152, DOI:10.14198/medieval.2012-2015.18.04

\title{
¿LOS MERCADERES SON EGUALADORS DEL MÓN? AUTÓCTONOS Y EXTRANJEROS EN EL COMERCIO BAJOMEDIEVAL DE VALENCIA
}

\author{
David Igual Luis ${ }^{1}$ \\ (Universidad de Castilla-La Mancha)
}

\section{RESUMEN}

El artículo realiza un balance sobre las relaciones que se establecieron, en la ciudad de Valencia, entre los miembros autóctonos de su sociedad y los mercaderes extranjeros instalados en ella durante los siglos XIV y XV. Este balance se basa en las fuentes y la investigación específicas sobre el tema, pero pretende también comparar el caso valenciano con el de otros países ibéricos de la Corona de Aragón y con distintas regiones de Europa y el Mediterráneo. Así, partiendo de la propia documentación y de algunas consideraciones historiográficas generales sobre los asuntos de extranjería y nacionalidad, se abordan dos de los planos que permiten analizar la presencia mercantil foránea en Valencia: por un lado, las condiciones de permeabilidad que ofrecía la sociedad local para la inserción personal y económica de los inmigrantes; por

1 Doctor en Historia. Profesor Titular. Departamento de Historia Medieval. Facultad de Humanidades de Albacete. Universidad de Castilla-La Mancha. Campus Universitario s/n. 02071. Albacete. C.e: david.igual@uclm.es

Este trabajo forma parte de los estudios desarrollados por el autor dentro de dos proyectos de investigación. Uno, financiado por el Ministerio de Ciencia e Innovación y dirigido desde la Universidad de Valencia por Paulino Iradiel Murugarren: "Élites sociales y estructuras económicas comparadas en el Mediterráneo occidental (Corona de Aragón, Francia e Italia) en la Baja Edad Media" (años 2008-2011, referencia HAR2008-06039). El otro, subvencionado por la Junta de Comunidades de Castilla-La Mancha y dirigido desde la Universidad de Castilla-La Mancha por José Antonio Jara Fuente: "Hombres de negocios: mercaderes y financieros en las ciudades castellanomanchegas en la Baja Edad Media" (años 2010-2013, referencia PEII10-0070-8208). 
el otro, contradictoriamente, las lógicas de enfrentamiento entre autóctonos y foráneos que hacían aflorar la extranjería como hecho de exclusión. El contraste entre ambos planos condujo a soluciones que son difíciles de presentar en términos unilaterales, por la enorme variedad no sólo de las coyunturas, sino también de las circunstancias socioprofesionales, personales y colectivas que reunían los grupos de extranjeros.

Palabras clave: Valencia. Mercaderes. Siglos XIV-XV. Extranjería.

\begin{abstract}
The article makes a balance on the relations established, in the city of Valencia, by the native members of the society and the foreign merchants installed there during the fourteenth and the fifteenth centuries. This balance is based on the specific sources and research on the subject, but it also tries to compare the Valencian case with the other Iberian countries of the Crown of Aragon and with different regions from Europe and the Mediterranean. Thus, starting from the documentation and general historiographical considerations on issues of the condition of foreigner and nationality, two questions are addressed that allow to analyze the foreign mercantile presence in Valencia: on the one hand, the conditions of permeability that offered the local society for personal and economic integration of immigrants; on the other, paradoxically, the logics of confrontation between natives and aliens that made arise the condition of foreigner as a fact of exclusion. The contrast between both questions led to solutions that are difficult to display in unilateral terms, by the enormous variety not only of the conjunctures, but also of the social, professional, personal and collective circumstances that characterized the groups of foreigners.

Keywords: Valencia, Merchants, Fourteenth and Fifteenth centuries, The condition of foreigner.
\end{abstract}

Me parece innegable que, en los últimos tiempos, los estudios sobre la economía medieval han permitido avanzar en lo que se ha calificado como el "redescubrimiento" o la "renovación de los parámetros historiográ-

2 EPSTEIN, S.R., "Nuovi sviluppi nella storia economica", en SABATÉ, F. - FARRÉ, J. (coords.), Medievalisme: noves perspectives. VII Curs d'Estiu Comtat d'Urgell (celebrado en Balaguer, 10-12 de julio de 2002), Lérida, 2003, pp. 36-38; IRADIEL MURUGARREN, P., "La crisis bajomedieval, un tiempo de conflictos", en IGLESIA DUARTE, J.I. de la (coord.), Conflictos sociales, políticos e intelectuales en la España de los siglos XIV y XV. XIV Semana de Estudios Medievales (celebrada en Nájera, 4-8 de agosto de 2003), Logroño, 2004, pp. 28-29. 
ficos" ${ }^{13}$ acerca del mercado. La revisión consiguiente de la teoría y la práctica de los fenómenos mercantiles se ha hecho, desde el medievalismo, en paralelo a las reflexiones surgidas también a partir del examen de otras épocas históricas. En todos los casos, las ideas más recientes sobre el tema han insistido en viejos asuntos, han abordado argumentos nuevos o han replanteado ciertos análisis, subrayando siempre de paso la complejidad humana y material que revestían los intercambios pretéritos ${ }^{4}$.

En esa línea, está clara la contribución de los mercados al dinamismo de las sociedades, entre otras cosas al promover la circulación de recursos, el estímulo a la producción y el consumo, la multiplicación de las oportunidades de inversión y el sostenimiento del trabajo y la acumulación económica. Pero, aunque sólo sea como resultado de las inquietudes despertadas por la crisis que Europa vive hoy y por la casi inevitable interacción pasado-presente que la misma conlleva, poco a poco se tiende a enfatizar determinados problemas del desarrollo comercial y financiero 5 . Estos obstáculos irían desde los escenarios de vulnerabilidad que azotaban dicho desarrollo, hasta la directa ineficiencia que manifestaban en ocasiones los mecanismos mercantiles y que podían llegar a perturbar los propios factores de crecimiento ${ }^{6}$.

Desde luego, también estaría entre las posibles dificultades del mercado la resolución de los episodios de exclusión, negociación y promoción de los que trata este dossier y que se verificaron, asimismo, en la economía y el comercio urbanos de la Baja Edad Media. En tales mundos no dejaron de sucederse entonces lances de integración o segregación entre grupos humanos,

3 SESMA MUÑOZ, J.Á. - LALIENA CORBERA, C., "Crecimiento económico y formación de los mercados en Aragón (1200-1350)", en ÍDEM - ÍDEM (coords.), Crecimiento económico y formación de los mercados en Aragón en la Edad Media (1200-1350), Zaragoza, 2009, p. 11.

4 Compruébese lo que digo en el texto a través de las distintas contribuciones de AMMANNATI, F. (a cura di), Dove va la storia economica? Metodi e prospettive, secc. XIII-XVIII. Atti della Quarantaduesima Settimana di Studi dell'Istituto Internazionale di Storia Economica "F. Datini" (celebrada en Prato, 18-22 de abril de 2010), Florencia, 2011; y de El mercat: un món de contactes i intercanvis. XVI Curs d'Estiu Comtat d'Urgell (celebrado en Balaguer, 6-8 de julio de 2011), Lérida, en prensa. Para la Corona de Aragón medieval, véase también FURIÓ, A., "Producción agraria, comercialización y mercados rurales en la Corona de Aragón", en SESMA MUÑOZ, J.Á. (coord.), La Corona de Aragón en el centro de su historia, 1208-1458. Aspectos económicos y sociales, Zaragoza, 2010, pp. 363-425.

5 Inquietudes e interacción visibles, por ejemplo, en ASKENAZY, P. y otros, Manifiesto de economistas aterrados, Madrid, 2011, y en RUIZ RODRÍGUEZ, J.I. - MOCHÓN, F., El colapso de Occidente. La crisis ante la Historia, Barcelona, 2011.

6 Es lo que se resalta, desde el modelo concreto de los circuitos financieros europeos de finales del Medievo, en IGUAL LUIS, D., "La circulación de capitales. El mundo financiero europeo en la Baja Edad Media", en El mercat ..., cit., en prensa. 
muy especialmente si estos grupos podían caracterizarse como autóctonos o como extranjeros dentro de cada realidad local. No en balde, por ejemplo en España, la documentación del período refleja constantemente ideas de discriminación y de separación de los individuos según su condición indígena o $\mathrm{no}^{7}$. Incluso, ya a escala europea, las ciudades se convirtieron en este marco en buenos bancos de pruebas de expresiones xenófobas ${ }^{8}$.

Como ha demostrado la investigación, el reino de Valencia y su capital constituyen durante los siglos XIV y XV espacios privilegiados de observación de estas circunstancias. El impacto del mercado sobre el área y la confluencia en ella de operadores de múltiples procedencias son hechos ya bien conocidos. También lo son las relaciones de cooperación y conflicto que, en función del origen local o foráneo de los mercaderes, se establecieron entre los diversos agentes y afectaron a veces a las instituciones políticas. El balance que pretendo ofrecer en el artículo sobre dichas relaciones destaca, de entrada, por sus detalles concretos y por las dinámicas globales que retrata. Pero sirve a la par para ilustrar la dualidad de elementos dinamizadores y problemáticos del comercio que antes he resaltado, sobre todo si, como quiero hacer asimismo aquí, el caso valenciano se compara y contextualiza con el de otros países ibéricos de la Corona de Aragón y con distintas regiones de Europa y el Mediterráneo?.

\section{LA DIVERSA CONCEPCIÓN DEL COMERCIO Y LOS EXTRANJEROS: APUNTES INICIALES}

Siempre en Valencia, las fuentes bajomedievales llegan a reproducir con claridad las diferentes perspectivas que reunían los tráficos mercantiles. En 1450, las autoridades de la capital sostenían en una carta que los mercaders

7 LALINDE ABADÍA, J., "Linserimento dello straniero nelle comunità politiche della Spagna: un profilo giuridico", en ROSSETTI, G. (a cura di), Dentro la città. Stranieri e realtà urbane nell'Europa dei secoli XII-XVI, Nápoles, 1989, p. 48.

8 MITRE FERNÁNDEZ, E., La ciudad cristiana del Occidente medieval (c. 400 - c. 1500), Madrid, 2010, p. 127.

9 Para los temas que acabo de señalar, la centralidad en el caso valenciano y su comparación con otros territorios ya las apunté en las ponencias que impartí en dos seminarios celebrados en la Facultad de Filosofía y Letras de la Universidad de Alicante. La primera se titulaba "Extranjería y nacionalidad en las comunidades mercantiles mediterráneas de Valencia (siglo XV)", y se integró en el seminario Las señas de identidad institucionales, forales y culturales del Reino de Valencia en la Edad Media (30 de octubre de 2009). La segunda versaba sobre "¿Los mercaderes son egualadors del món? Autóctonos y extranjeros en el comercio bajomedieval de la Corona de Aragón", y se incluyó en la jornada Entre la integración y la segregación: mecanismos de exclusión, negociación y promoción en las sociedades bajomedievales (22 de octubre de 2010). Precisamente, ambas ponencias constituyen el punto de partida del presente artículo. 
són dits egualadors del món. Éstas son justo las palabras con las que encabezo el título de mi trabajo. Y a ellas, las citadas autoridades todavía añadían que, lla on mercaderia.s fa la terra és augmentada e prosperada, e on no, és deserta e destroÿda. Pocos años después, en otra carta de 1454, los propios dirigentes de la ciudad de Valencia insistían en presentar a los mercaderes como aquellas personas por quienes en la major part lo món és sostengut ${ }^{10}$. Es verdad que, en ocasiones, lo que motivaba la redacción de frases como las señaladas eran los cuantiosos ingresos fiscales que suponía para el erario el quehacer de los comerciantes. Pero, en cualquier caso, dichas frases se sitúan en una línea de alabanza del oficio mercantil y de los efectos beneficiosos de su actividad para el conjunto social que arraigó, a finales de la Edad Media, entre las élites urbanas no sólo de Valencia, sino también de otras zonas del Oriente peninsular aragonés ${ }^{11}$.

Las visiones en positivo de lo comercial, sin embargo, se volvían mucho más matizadas cuando las ciudades de la Corona y sus naturales y vecinos debían hacer frente a la competencia de operadores económicos extranjeros. Recuérdese que, desde el siglo XII en Aragón y Cataluña y desde el XIII en Mallorca y Valencia, la presencia de negociadores foráneos devino un rasgo estructural de los mercados urbanos y de su proyección regional, incluso sobre los ámbitos rurales. Hasta el Cuatrocientos, como se apreciará mejor en las páginas siguientes, esto hizo entrar en juego factores de complementariedad o de concurrencia con la labor de los profesionales nativos, de lo que emanaron unos vínculos entre los distintos grupos que no fueron ni unánimes desde las ópticas social e institucional, ni constantes desde el punto de vista temporal ${ }^{12}$. De nuevo, la reseña inicial de algunos documentos del Bajo Medievo brindará muestras muy evidentes de estas circunstancias variables.

Por ejemplo, de 1403 a 1409, diversas discrepancias políticas y fiscales entre las coronas de Aragón y Castilla condujeron a la ruptura de lazos co-

10 RUBIO VELA, A. (ed.), Epistolari de la València medieval (II), Valencia/Barcelona, 1998, pp. 209 (documento de 1450) y 237 (documento de 1454).

11 IGUAL LUIS, D., "Política y economía durante la Baja Edad Media. El papel de la monarquía en el comercio exterior valenciano", en BARRIO BARRIO, J.A. (ed.), Los cimientos del Estado en la Edad Media. Cancillerías, notariado y privilegios reales en la construcción del Estado en la Edad Media, Alcoy, 2004, pp. 251-252; ÍDEM, "La formación de élites económicas: banqueros, comerciantes y empresarios", en SESMA MUÑOZ (coord.), La Corona de Aragón ..., cit., pp. 143-144 y 160.

12 NAVARRO ESPINACH, G., "La presencia de grupos extranjeros en la Corona de Aragón (siglos XIII-XV)", en SESMA MUÑOZ (coord.), La Corona de Aragón ..., cit., pp. 161-190; IGUAL LUIS, "La formación ...", cit., p. 148; CARRÈRE, C., Barcelona 1380-1462. Un centre econòmic en època de crisi, vol. I, Barcelona, 1977, p. 21. 
merciales entre ambas. Semejantes hechos alteraron los tratos de los sujetos interesados en el intercambio bilateral, incluyendo los de gentes que provenían de fuera de los reinos hispánicos: el sedero florentino Gregorio Dati, aludiendo en su libro segreto a las medidas adoptadas entonces per lo re di Ragona contro a chi mandasse in Castella le robe, las calificaba de leggi fatte odiosamente $^{13}$. Pese a esto, aún en medio de tales circunstancias, en una misiva enviada por el soberano aragonés Martín el Humano a su homólogo castellano, en 1405, se afirmaba que en los regnos á maior habundancia de todas mercaderías quanto más en aquéllos ha mayor freqüentació de gentes estrangeras ${ }^{14}$. Consta aquí de modo palpable una postura favorable al aperturismo mercantil, y a la actuación en los territorios propios de individuos y empresas foráneos. Algo igual a lo que, en 1416, 1419 y 1423, defendieron otra vez las autoridades de la ciudad de Valencia en referencia específica a los mercaderes venecianos, castellanos y genoveses. En estas fuentes se aseguraba que los mercaders de nacions stranyes solían ser bé tractats e molt favorits por la monarquía (en 1416); que a los castellanos hasta se les consideraba en la capital valenciana com a propris conciutadans, axí bé e mils que.ls que són originaris e ciutadans nostres (en 1419); y que había sido conveniente favorir los dits mercaders strangers per los grans profits e utilitats que aportaban a los habitantes de Valencia y su reino (en 1423) ${ }^{15}$.

Por el contrario, junto a estas actitudes, no faltaron desde 1200 (y más desde 1300) posicionamientos radicalmente opuestos a los movimientos económicos extranjeros. Al respecto, uno de los momentos más destacados se dio en 1401. Ese año, los síndicos parlamentarios de Valencia, Barcelona, Mallorca, Tortosa y Perpiñán acusaron a los mercaderes florentinos y a otros italianos de devorar y empobrecer las tierras donde intervenían, a causa de su potencia financiera y, en particular, de su capacidad para maquinar subtils enginys e agabellats e damnats contractes ${ }^{16}$. Estas alegaciones per-

13 GARGIOLLI, C. (a cura di), Il Libro Segreto di Gregorio Dati, Bolonia, 1968, p. 59.

14 FERRER I MALLOL, M.T., "La ruptura comercial amb Castella i les seves repercussions a València (1403-1409)", en Primer Congreso de Historia del País Valenciano (celebrado en Valencia, 14-18 de abril de 1971), vol. II: Prehistoria. Edades Antigua y Media, Valencia, 1980, p. 675.

15 RUBIO VELA (ed.), Epistolari ..., cit., pp. 200 (documento de 1419), 231 (documento de 1416) y 235 (documento de 1423). Como se ha indicado antes, y como reafirma el tenor de estos tres documentos, también en el trasfondo de algunas de las frases reproducidas estaba la abundante recaudación impositiva que se obtenía del comercio extranjero.

16 IGUAL LUIS, D., Valencia e Italia en el siglo XV. Rutas, mercados y hombres de negocios en el espacio económico del Mediterráneo occidental, Castellón, 1998, p. 42. Una visión más reciente de los acontecimientos de 1401, y de su contexto general, consta en SOLDANI, M.E., Uomini d'affari e mercanti toscani nella Barcellona del Quattrocento, Barcelona, 2010, pp. 292-296. 
seguían expulsar de la Corona de Aragón a determinados operadores que se habían asentado en ella, sobre todo toscanos. Pero recogían en paralelo, sin duda, los resquemores que despertaban entre los protagonistas autóctonos del mercado las estrategias, muchas veces juzgadas como invasivas, que empleaban las compañías italianas a la hora de penetrar en las redes locales de negociación.

No obstante, dichos resquemores existían también en sentido inverso. Simone Bellandi, delegado en Barcelona de la famosa compañía de Francesco di Marco Datini de Prato, escribía en 1396 que los proveedores catalanes y valencianos de lana se comportaban de forma sospechosa, ya que mantenían altos los precios al creer que los compradores toscanos "eran de oro" (tutti siamo oro), es decir, al creer que estos compradores poseían siempre abundantes reservas monetarias. El mismo Bellandi y en la misma fecha tildaba a Cataluña, Mallorca y Valencia de paese de diavolo, por cuanto los extranjeros se veían casi obligados en las tres áreas a comerciar sólo en nombre propio o a través de procuraciones, lo que debía ser ajeno a las prácticas contractuales a las que Bellandi estaba acostumbrado ${ }^{17}$. Con opiniones así, no es sorprendente que el desencadenamiento de dificultades más o menos puntuales entre los forasteros incrementara su percepción negativa: si el ya mencionado Gregorio Dati resumía los apuros empresariales por los que atravesó en nuestra península antes de 1410 con un genérico le falsità di Spagna $^{18}$, el también florentino Giovanni Cotrugli describía en 1447 a los catalanes como gente molto senestra, al tener que abandonar Barcelona en una época de intensa ofensiva política y social contra las aspiraciones de los toscanos residentes alli ${ }^{19}$.

\section{ALGUNAS CONSIDERACIONES GENERALES SOBRE EXTRANJERÍA, IDENTIDAD Y NACIONALIDAD}

Por aisladas y dispersas que sean, las noticias anteriores señalan algunas de las contraposiciones que podían darse entre grupos comerciales de diferentes orígenes, en una sociedad medieval como la valenciana y, por extensión, aragonesa. En último extremo, y como en otros lugares, ayudan a poner sobre la mesa la vieja cuestión de quién terminaba por beneficiarse más de los establecimientos foráneos en un espacio dado: ¿la realidad receptora o

17 CARRÈRE, Barcelona ..., cit., pp. 22 y 34.

18 GARGIOLLI (a cura di), Il Libro Segreto ..., cit., pp. 89-90.

19 TREPPO, M. del, Els mercaders catalans i l'expansió de la corona catalano-aragonesa al segle XV, Barcelona, 1976, p. 267; SOLDANI, Uomini d'affari ..., cit., p. 323. 
los extranjeros? ${ }^{20}$ De hecho, estos establecimientos y la ascendencia étnica o geográfica de los operadores, al lado del parentesco y la confesión religiosa, constituyeron bases comunes en la formación de redes mercantiles por todo el universo euromediterráneo ${ }^{21}$. No se olvide que la circulación multilateral de personas, de diversas condiciones, fue clave en la construcción del sistema continental de relaciones económicas durante las centurias finales de la Edad Media.

En parte, la comprensión de esta dinámica exige ubicarla en los canales de desplazamiento migratorio y de movilidad social que vertebraron los mercaderes del período, al igual que otros grupos coetáneos ${ }^{22}$. Pero, de acuerdo con los objetivos del artículo, me interesa más subrayar la contribución de tal variable al fenómeno fundamental de la estraneità. La actualidad de la que continúa disfrutando en la historiografía el asunto de los extranjeros no evita que, al respecto, siga siendo válido lo que se afirmó desde Italia hace tiempo: en el Bajo Medievo, y al menos para los ámbitos ciudadanos, parece cierto que bastaba salir de las murallas y andar unas millas para sentirse y ser considerado extranjero; por eso, dichos extranjeros fueron entonces componentes esenciales de los variopintos mundos urbanos, sobre todo cuando éstos eran costeros o se situaban a lo largo de vías de comunicación destacadas ${ }^{23}$.

El tema requiere abordar, por supuesto, una vertiente legal. En Valencia, la monarquía definía en 1239 como extraneus a quien non erit de regno Valencie. Qué significativo es que esta disposición aparezca en un privilegio

20 FUSARO, M., "Gli uomini d'affari stranieri in Italia", en FRANCESCHI, F. y otros (a cura di), Il Rinascimento italiano e l'Europa, vol. IV: Commercio e cultura mercantile, Treviso-Costabissara, 2007, p. 376.

21 IRADIEL MURUGARREN, P., "El siglo de oro del comercio valenciano", en AGUILAR CIVERA, I. (coord.), El comercio y el Mediterráneo. Valencia y la cultura del mar, Valencia, 2006, pp. 124-125.

22 Recogiendo una larga tradición de estudios al respecto, así lo ha subrayado últimamente Giuseppe Petralia en dos artículos: "Problemi della mobilità sociale dei mercanti (secoli XII-XIV, Italia e Mediterraneo europeo)", en CAROCCI, S. (a cura di), La mobilità sociale nel Medioevo, Roma, 2010, pp. 247-271; "Migrations marchandes: dynamique et rythmes de la mobilité des Toscans avant (et après) la Peste Noire", en Des sociétés en mouvement. Migrations et mobilité au Moyen Âge. XLe Congrès de la Société des historiens médiévistes de l'Enseignement supérieur public (celebrado en Niza, 4-7 de junio de 2009), París, 2010, pp. 111-120.

23 ASCHERI, M., "Lo straniero nella legislazione statutaria e nella letteratura giuridica del Tre-Quattrocento: un primo approccio", en Forestieri e stranieri nelle città bassomedievali. Atti del Seminario Internazionale di Studio (celebrado en Bagno a Ripoli, Florencia, 4-8 de junio de 1984), Florencia, 1988, pp. 7-8. Sobre la actualidad historiográfica del tema de la extranjería, véase NAVARRO ESPINACH, "La presencia ...", cit., pp. 161-167. 
dedicado a regular varios impuestos, algunos sobre el comercio, de los que se eximía a los pobladores de la capital y su término. En consecuencia, se hacía necesario delimitar quiénes iban a beneficiarse de la franquicia y a ser tratados, a esos efectos, como valencianos ${ }^{24}$. Hacia 1271 probablemente, el fuero del reino que traducía en catalán tal prerrogativa recalcaba que hom estrayn es aquell qui no serà del regne de València, pero precisaba también que el vecino de Valencia era qui jurarà estatge o habitació de la ciutat o aquí haurà sa muller o tendrà aquí son cap major ${ }^{25}$. Más tarde, en 1306, el soberano calificaba de extranei a qui non sunt de terra nostra, es decir, a los no pertenecientes a la Corona de Aragón, una atribución reiterada en los documentos hasta el xv y matizada con la consideración de los autóctonos como naturales y originarios de las tierras del rey ${ }^{26}$.

Estos breves apuntes, obviamente incompletos, muestran una doble combinación posible tanto de conceptos jurídicos (extranjería, vecindad, naturaleza), como de esferas territoriales e institucionales de aplicación (ciudad, reino, corona). Unas distinciones, en especial la segunda, que podían poseer importantes implicaciones. Si cambiamos la escala de análisis, la investigación sobre los denominados "lombardos" que estaban instalados en regiones medievales del centro de Europa, por ejemplo, ha hecho patente que las condiciones de integración social y ascenso político de los inmigrantes eran mejores cuando se situaban bajo el amparo de autoridades de tipo real, por la necesidad que éstas tenían de financieros y prestamistas, que cuando lo hacían en ciudades autónomas ${ }^{27}$. A otro nivel, y también por ejemplo, en Mallorca a partir del siglo XIII coexistieron las categorías de ciudadano de la capital y de natural del reino. Ambas emanaban respectivamente de las jurisdicciones municipal y monárquica y, en el contexto de la época, podían llegar a denotar criterios divergentes en la diferenciación de la autoctonía y la alteridad: si para los munícipes la extranjería se oponía

24 CORTÉS, J. (a cura de), Liber privilegiorum civitatis et regni Valencie. I. Jaume I (12361276), Valencia, 2001, pp. 99-100 (privilegio de 1239-XI-22).

25 GUAL CAMARENA, M., Vocabulario del comercio medieval. Colección de aranceles aduaneros de la Corona de Aragón (Siglos XIII y XIV), Tarragona, 1968, p. 119; LÓPEZ ELUM, P., Los orígenes de los Furs de València y de las cortes en el siglo XIII, Valencia, 1998 , pp. 288 y 293.

26 IGUAL LUIS, "Política y economía ...", cit., p. 264 (dato de 1306); SIMÓ SANTONJA, V.L., Estatuto de los extranjeros en el antiguo derecho valenciano, Sagunto, 1973, pp. 8990 (documentación del siglo XV).

27 SCARCIA, G., "Il radicamento fuori patria", en BORDONE, R. - SPINELLI, F. (a cura di), Lombardi in Europa nel Medioevo, Milán, 2005, p. 177; EADEM, "Comburgenses et cohabitatores: aspetti e problemi della presenza dei "lombardi" tra Savoia e Svizzera", en PETTI BALBI, G. (a cura di), Comunità forestiere e "nationes" nell'Europa dei secoli XIII-XVI, Nápoles, 2001, pp. 113-133. 
sólo a la ciudadanía, para la realeza marcaba lo contrario de la identidad llamémosle "nacional"28.

Al final, muchos elementos conducen a corroborar el valor polisémico que conservaba la noción legal del extranjero en las postrimerías de la Edad Media o, dicho de otro modo, el poco consenso que las gentes de entonces alcanzaron a la hora de codificar el concepto con plena exactitud ${ }^{29}$. Y ello a pesar de que, por lo menos en España, se avanzó desde el siglo XIV en vincular la divisoria en este terreno más con el ius domicili (la residencia, la domiciliación) que con el ius sanguinis (el nacimiento) ${ }^{30}$. Sin embargo, con ser trascendentes las derivaciones que tuvieron los preceptos normativos, la concreción material y práctica de los rasgos ligados a la extranjería manifiesta aún mayores dosis de complicación.

Es evidente la profunda diversidad interna que escondía el fenómeno, por encima del significado que en él lograron los mercaderes. De entrada, porque los estatus socioeconómicos y profesionales del conjunto de sus protagonistas eran múltiples, con las lógicas repercusiones sobre los motivos de su desplazamiento y las perspectivas que se les abrían en las zonas de $\operatorname{acogida}^{31}$. Pero las diferencias religiosas también eran indicadores acentuados de alteridad, sobre todo si se seguía un credo minoritario dentro de una determinada sociedad y, por ello, éste aparecía marginado y hasta observado normalmente con hostilidad, como sucedía con los judíos y los musulmanes en territorio cristiano $^{32}$. Además, la distancia física y/o cultural entre los lugares de salida y de llegada de la persona afectada la impregnaban asimismo de connotaciones matizadas: con independencia de las calificaciones jurídicas, en la realidad no era igual quien arribaba a una ciudad desde el

28 NAVARRO ESPINACH, "La presencia ...", cit., p. 172, donde se utiliza la cita de PIÑA HOMS, R., "La condición de natural del reino de Mallorca. Bases para una aproximación histórica a la ciudadanía mallorquina", en Anuario de Historia del Derecho Español, LV, Madrid 1985, pp. 307-332.

29 Del "valor polisémico" del concepto se habla en LADERO QUESADA, M.Á., "Unidad y diversidad en la España medieval. En torno a las ideas de nación, patria y estado", en Fundamentos medievales de los particularismos hispánicos. IX Congreso de Estudios Medievales (celebrado en León, 2003), León, 2005, p. 21. Y del "poco consenso", en AMELANG, J.S., "Cities and foreigners", en CALABI, D. - TURK CHRISTENSEN, S. (eds.), Cultural Exchange in Early Modern Europe, vol. II: Cities and Cultural Exchange in Europe, 1400-1700, Cambridge, 2007, p. 42.

30 LALINDE ABADÍA, "Linserimento ...", cit., p. 54.

31 PINTO, G., "Forestieri e stranieri nell'Italia comunale: considerazioni sulle fonti documentarie", en Forestieri e stranieri ..., cit., pp. 20-21; ÍDEM, "Gli stranieri nelle realtà locali dell'Italia basso-medievale: alcuni percorsi tematici", en ROSSETTI (a cura di), Dentro la città ..., cit., pp. 26-27.

32 AMELANG, "Cities ...", cit., p. 43. 
campo circundante o desde otra ciudad del mismo país, que quien lo hacía desde espacios alejados y quizá con lenguas y costumbres distintas. Por eso no han faltado los expertos que han propuesto separar, desde el vocabulario del presente, al "extranjero" (que sería quien no pertenecía a la etnia) del "forastero" (quien sí era de la misma etnia, aunque formaba parte de otra realidad sociopolítica $)^{33}$.

El estudio de los comerciantes, en sus asentamientos en el exterior, enfatiza las posibles divergencias de rango y fortuna que albergaban los emigrantes. Entre los italianos que poblaban los reinos hispánicos durante el siglo XV, existía una élite de operadores que gestionaba sus propias redes empresariales y mantenía sólidos enlaces internacionales. Pero también cabe encontrar numerosos agentes medianos y menores que actuaban a título individual, dependían de compañías mayores o, incluso, eran sujetos humildes que buscaban posiciones de vida más desahogadas ${ }^{34}$. De todas maneras, para los grandes mercaderes casi de cualquier procedencia, el establecerse en tierras extrañas asumía tonos particulares. Ello fue el efecto de su carácter de hombres de negocios en los términos de la etapa bajomedieval, de su intervención en las estrategias expansivas de los países y las empresas de origen, de su importancia a la hora de erigir vínculos de amplias dimensiones y, finalmente, de su inserción por doquier en ambientes económicos cosmopolitas. Así, de nuevo más allá del diseño legal, la concepción extranjera de esos grandes mercaderes en las plazas de radicación llegaba a veces a difuminarse, en medio del desarrollo cotidiano de unas transacciones en las que se movían usualmente con familiaridad y sin enormes dificultades, y que les llevaban a relacionarse con compatriotas y con tratantes de otras comunidades $^{35}$. En este universo, y salvando la infinita disparidad de situaciones locales y coyunturales, es normal que los mercaderes de cierta extracción pudieran constituir en Europa y el Mediterráneo, en muchas ocasiones

33 ROSSETTI, G., "Introduzione", en EADEM (a cura di), Dentro la città ..., cit., p. XIV; FUSARO, "Gli uomini d'affari ...", cit., p. 371. En un trabajo ya clásico sobre los mercaderes extranjeros en Valencia, José Hinojosa apuntó distinciones que iban en una línea parecida a la que acabo de comentar en el texto (HINOJOSA MONTALVO, J., "Sobre mercaderes extrapeninsulares en la Valencia del siglo XV", Saitabi, 26, Valencia 1976, p. 60). Pero acerca de la problemática del vocabulario en el asunto histórico de la extranjería, y en la comparación pasado-presente, véase más en general AMELANG, "Cities ...", cit., pp. 42-43.

34 IGUAL LUIS, D., "Banqueros y comerciantes italianos en España en tiempos de los Reyes Católicos", en CASADO ALONSO, H. - GARCÍA-BAQUERO, A. (eds.), Comercio y hombres de negocios en Castilla y Europa en tiempos de Isabel la Católica, Madrid, 2007, pp. 159-161.

35 PINTO, "Gli stranieri ...", cit., p. 30. 
hasta la Edad Moderna, una presencia deseable frente a otras categorías de inmigrantes ${ }^{36}$.

Los dos párrafos anteriores apuntan parcialmente, asimismo, otros elementos a tener en cuenta en la percepción histórica de lo extranjero. Son los que conectan con la proyección imaginaria o mental del fenómeno o, desde una óptica más global, con su vertiente cultural en sentido amplio ${ }^{37}$. De hecho, el énfasis reciente (en el medievalismo y fuera de él) en el examen de las identidades sociales y territoriales está permitiendo precisar justo algunos de estos aspectos, también en temas de mercaderes y extranjería. Anótese que, en términos sociales, la identidad implica la conciencia que cada uno tenía de pertenecer a un grupo de individuos, opuesto a otros, y la voluntad de definirse como su miembro ${ }^{38}$. Apreciada así, desde luego, la identidad no sólo conlleva la contraposición entre un "yo" y un "otro", sino que se construye mediante un proceso dinámico y dialéctico, necesariamente contextualizado en el seno de unas circunstancias determinadas, y que además es capaz de generar actos, comenzando por promover estilos de vida acordes en teoría con ciertas reglas de comportamiento ${ }^{39}$.

Entre los emigrantes y las gentes residentes en tierras foráneas, las elaboraciones identitarias afectaban al menos a dos clases de binomios: una, la producida con la mezcla de rasgos viejos y rasgos nuevos o, lo que es lo mismo, de una identidad de origen y una identidad adquirida en las zonas de permanencia, bien reflejada por ejemplo en los posibles cambios lingüísticos y formales de los

36 AMELANG, "Cities ...", cit., p. 44.

37 Es lo que se destacó también hace tiempo en D'HAENENS, A., "Essere stranieri nel Medioevo", en ROSSETTI (a cura di), Dentro la città ..., cit., pp. 17-21.

38 AURELL, J., "Reading Renaissance Merchants' Handbooks: Confronting Professional Ethics and Social Identity", en EHMER, J. - LIS, C. (eds.), The Idea of Work in Europe from Antiquity to Modern Times, Farnham, 2010, p. 82. Sobre la eclosión actual del tema de las identidades, particularmente en España, véase GARCÍA DE CORTÁZAR, J.Á., “¿'Atomización'? de las investigaciones y ¿'regionalismo”? de las síntesis en Historia Medieval en España: ¿búsqueda de identidades o simple disminución de escala?”, en La Historia Medieval hoy: percepción académica y percepción social. XXXV Semana de Estudios Medievales (celebrada en Estella, 21-25 de julio de 2008), Pamplona, 2009, pp. 345-347.

39 JARA FUENTE, J.A., "Introducción: Memoria de una identidad (de identidades). Castilla en la Edad Media", en ÍDEM y otros (eds.), Construir la identidad en la Edad Media. Poder y memoria en la Castilla de los siglos VII a XV, Cuenca, 2010, p. 9; NAVARRO ESPINACH, G., "Los protagonistas del comercio: Oficios e identidades sociales en la España bajomedieval", en IGLESIA DUARTE, J.I. de la (coord.), El comercio en la Edad Media. XVI Semana de Estudios Medievales (celebrada en Nájera y Tricio, 1-5 de agosto de 2005), Logroño, 2006, pp. 186-187; ORTUÑO MOLINA, J., "Definiciones identitarias y conflictividad en la Edad Media. Las relaciones de frontera entre los reinos cristianos de Murcia y Valencia en los siglos XIII-XVI", Anuario de Estudios Medievales, 41/1, Barcelona 2011, pp. 76-77 y 95. 
nombres personales y familiares de los desplazados; la otra, la conseguida a través de la hipotética creación de un discurso ideológico o de autoidentidad dentro de una comunidad extranjera, en contraste mayor o menor con la sociedad hospedante y sus actitudes de aceptación o rechazo respecto a la alteridad ${ }^{40}$. Ni que decir tiene que un importante asunto que subyace en estas cuestiones es el de la existencia de realidades y/o sentimientos nacionales, ligados por descontado a la progresiva constitución de naciones y nacionalidades, sobre todo desde el momento en que tales conceptos también han sido históricamente herramientas que marcaban la exclusión y la oposición entre grupos ${ }^{41}$.

A finales de la Edad Media, es patente en Europa el desarrollo de conciencias nacionales. Más problemas suponen las evidencias de que la propia palabra "nación" y sus elementos asociados no siempre significaban exactamente lo mismo entonces que ahora, que es complicado deducir el grado de extensión del ideario y la materialidad nacionales entre las élites y la restante masa social, y que incluso cabe efectuar distinciones entre países según la verdadera concreción de estas situaciones ${ }^{42}$. Además, en una línea de problematización parecida hay que recordar que, en la práctica cotidiana e individualizada de los sujetos económicos, bajo las calificaciones nacionales se ocultaban muchas veces intereses de diverso tipo. Ello explica que, como veremos después con casos específicos, las atribuciones de nacionalidad (o como mínimo de origen) a las personas pudieran llegar a ser nociones que me atrevo a definir como negociables según la cronología y los hechos en juego. Ello explica también que, durante los siglos XIV y XV, algunos de los operadores extranjeros dispersos por el continente reforzaran su imagen comunitaria hasta constituir lo que la documentación de la época y la historiografía denominan, precisamente, "naciones". Y éstas, sobre todo allí donde abundaban los mercaderes, se presentaban como auténticas redes sociales y empresariales $^{43}$.

40 PETRALIA, "Migrations marchandes ...", cit., p. 117; AMELANG, "Cities ...", cit., pp. 43-44 y 48; CRESPO SOLANA, A., "Introducción. Aspectos para unas visiones comparativas en el estudio de las comunidades mercantiles (siglos XVI al XIX)", en EADEM (coord.), Comunidades transnacionales: colonias de mercaderes extranjeros en el mundo atlántico (1500-1830), Madrid, 2010, p. 22.

41 ISAACS, A.K., "Nations and Nationalities in Historical Perspective': Clioh's third Notebook", en HÁLFDANARSON, G. - ISAACS, A.K. (eds.), Nations and Nationalities in Historical Perspective, Pisa, 2001, p. VII.

42 LADERO QUESADA, "Unidad y diversidad ...", cit., pp. 19-20; BOIS, G., La gran depresión medieval: siglos XIV-XV. El precedente de una crisis sistémica, Madrid-Valencia, 2001, pp. 167-169; PETTI BALBI, G., "Introduzione", en EADEM (a cura di), Comunità forestiere ..., cit., p. XIII.

43 IRADIEL MURUGARREN, "El siglo de oro ...", cit., pp. 124-125. 
En tal sentido, una aproximación inicial a dichas nationes de extranjeros remite a la existencia de un conjunto de personas vinculadas por una misma procedencia territorial, en el que se integraban diferentes sectores socioprofesionales $^{44}$. Pero, de manera más estricta y en relación especial con el ámbito mercantil, estas "naciones" eran comunidades organizadas y reconocidas que se dotaban de instituciones propias. Desde la experiencia italiana, Giovanna Petti Balbi ha venido recalcando su significado. Eran asociaciones privadas y voluntarias, puestas en marcha por hombres de negocios que moraban temporalmente en el extranjero. Éstos se agrupaban sobre la base de la proveniencia común para defender intereses y objetivos generales, alcanzaban a través de la mencionada "nación" un reconocimiento externo político y jurídico y, con tal soporte, se proponían como interlocutores directos de los poderes locales, sin por ello disminuir los lazos con la madrepatria o buscar su acomodo en una única zona de asentamiento. También, el carácter de "nación" envolvía ciertas formas de disciplina social, ya que sus integrantes podían verse obligados a cumplir normas particulares de conducta, a asumir exigencias financieras $y$, en ocasiones, a residir de modo más o menos cohesionado en torno a una calle o un barrio ${ }^{45}$. En cualquier caso, más allá de lo que las nationes comerciales implicaran en cuanto a singularizar a sus componentes con determinados rasgos culturales y lingüísticos, éstas suponían aplicar a los grupos afectados una identidad global. Y ello, a la vez, revertía en que dichos grupos podían desempeñar funciones políticas en la ciudad de inserción, tutelar a sus miembros, obtener garantías y privilegios para ellos y, en definitiva, vertebrar el doble eje de relación al que se veía sometida toda instalación mercantil en el exterior: hacia fuera y hacia dentro del propio colectivo extranjero.

\section{VOLVIENDO A VALENCIA: AVECINDAMIENTOS Y PERMEABILI- DAD SOCIAL}

Por lo que atañe a los vínculos de los grupos extranjeros hacia fuera, en conexión con la sociedad de acogida, el repaso del ambiente europeo hace emerger en general un amplio abanico de situaciones entre finales del Medievo y comienzos de la Modernidad. De forma simplificada, éstas irían desde los lugares y los momentos en que se detectan fuertes restricciones a la actividad foránea hasta aquellas realidades en que la ausencia de limita-

44 SOLDANI, Uomini d'affari ..., cit., p. 24.

45 PETTI BALBI, G., Negoziare fuori patria. Nazioni e genovesi in età medievale, Bolonia, 2005, p. 4; EADEM, "Le nationes italiane all'estero", en FRANCESCHI y otros (a cura di), Il Rinascimento italiano ..., cit., p. 399; EADEM, "Introduzione", cit., p. XV. 
ciones permitió a los inmigrantes ejercer una influencia considerable en las áreas receptoras. Incluso, la concreción de estas circunstancias diversas ha posibilitado apuntar la existencia entonces de ciudades más abiertas o más cerradas a la hora de admitir la llegada de desplazados ${ }^{46}$.

En medio de este panorama, y volviendo al ejemplo de Valencia y sus mercaderes, cabe afirmar ya que la estrategia de las instituciones locales y la práctica administrativa frente a los operadores extranjeros tendieron, a lo largo de los siglos XIV y XV, a la concesión de exenciones y facilidades de tránsito, a la apertura de los espacios y a la reducción de los costes. Con ello se pretendería favorecer la colocación en el mercado de los excedentes disponibles y el aumento de los beneficios del capital comercial. Pero dicho diagnóstico cuadraría también con el elevado grado de permeabilidad social, o por lo menos de aceptación, que en principio se produciría aquí en relación con los foráneos, entre otros motivos gracias a la función económica que éstos desarrollaban y al estadio de articulación de los sectores emprendedores autóctonos. Sin embargo, aunque tales argumentos puedan ser válidos para la mayoría de negociadores extranjeros instalados en la ciudad de Valencia, son particularmente aplicables a ciertas élites mercantiles de origen sobre todo italiano, cuyos movimientos se ajustaban bien a los índices de progreso urbano y de reforzamiento de las clases dominantes ${ }^{47}$.

La permanente variación de las coyunturas no impide que los síntomas de la citada permeabilidad proliferen, asimismo de modo constante, en el transcurso del Bajo Medievo valenciano y muy especialmente en el Cuatrocientos. Al respecto, es muy relevante lo ocurrido con los procesos de integración y/o naturalización de los extranjeros, que pasaban a veces por el trámite oficial de adquisición de la vecindad en la capital. En Valencia, la visión global de estos avecindamientos manifiesta algunos rasgos coincidentes con lo que se conoce de los mecanismos parangonables de obtención de la ciudadanía en otros territorios: que el acto de avecindarse respondía a una serie de intereses tanto por parte de los foráneos (lograr privilegios fiscales, ponerse a salvo de medidas punitivas y de expulsión, o consolidar las trayectorias de inserción en el universo local), como por parte de los grupos dirigentes urbanos (asegurar sus ritmos de reproducción social); que pudo darse progresivamente una política selectiva del municipio, buscando atraer a individuos y familias de rangos profesionales cualificados y con recursos

46 AMELANG, "Cities ...", cit., p. 53.

47 IRADIEL MURUGARREN, "El siglo de oro ...", cit., p. 124; CRUSELLES GÓMEZ, E., Los comerciantes valencianos del siglo XV y sus libros de cuentas, Castellón, 2007, pp. 71-72 y 76 . 
suficientes para dinamizar la vida de la ciudad; y que, al final, los avecindamientos incumbieron a un número reducido de personas entre los extranjeros y los inmigrantes, situadas éstas en muchas ocasiones en las categorías de mayor prestigio social y nivel económico del conjunto de los flujos humanos de llegada a la metrópoli48.

Desde el punto de vista jurídico, con la concesión de la ciudadanía, el nuevo vecino se comprometía a mantener la estancia legal en Valencia durante un mínimo de años estipulado, variablemente según períodos, entre cinco y diez. También debía cumplir con las obligaciones impositivas de la capital, a cambio de recibir sus franquicias, y consignar el acta de anulación de su anterior domicilio ${ }^{49}$. En otros núcleos continentales, ahora al contrario, la residencia estable, la propiedad de inmuebles, la contribución a los gastos de la urbe, y hasta la fama pública de ser reputados como verdaderos ciudadanos, eran condiciones previas exigidas a quienes aspiraban a conseguir la carta de vecindad ${ }^{50}$. No obstante, por encima de cualquier criterio administrativo, la comparación de los registros institucionales del avecindamiento con otros tipos documentales (por ejemplo, los notariales) permite matizar, en algunas oportunidades, el alcance real de tales expedientes de ciudadanía. De hecho, siempre en Valencia, el seguimiento efectuado para el siglo XV por las carreras personales y económicas de numerosos italianos afincados aquí, básicamente mercaderes, ofrece datos trascendentes.

48 CRUSELLES GÓMEZ, E., Los mercaderes de Valencia en la edad media (1380-1450), Lérida, 2001, pp. 60 y 76; ÍDEM, "Dinámica demográfica, red urbana e inmigración ciudadana en la Valencia bajomedieval", en Saitabi, 53, Valencia 2003, pp. 38-40 y 42; ÍDEM, Los comerciantes valencianos ..., cit., pp. 73-74. Consúltese también NAVARRO ESPINACH, G., "Política municipal y avecindamientos. Análisis de la emigración aragonesa a Valencia (1308-1526)", en Demografía y sociedad en la España bajomedieval, Zaragoza, 2002, pp. 97-128. A efectos comparativos, véase MUELLER, R.C., Immigrazione e cittadinanza nella Venezia medievale, Roma, 2010, sobre todo pp. 13 y 58-59; ROMANO, A., "La condizione giuridica di stranieri e mercanti in Sicilia nei secoli XIV-XV", en TREPPO, M. del (a cura di), Sistema di rapporti ed élites economiche in Europa (secoli XII-XVII), Nápoles, 1994, p. 125; y SOLDANI, Uomini d’affari ..., cit., pp. 131-139. Sobre los intereses que podían tener los foráneos para avecindarse en un lugar, recuérdese que los pobladores de Valencia y su término estaban exentos de varios impuestos, como ocurría asimismo con los ciudadanos de Barcelona (SOLDANI, Uomini d'affari ..., cit., p. 135).

49 CABANES PECOURT, M.D., Avecindados en la ciudad de Valencia en la época medieval. Avehinaments (1308-1478), Valencia, 2008, pp. 11-19.

50 Condiciones así, en todo o en parte, se daban en ciudades como Venecia y Bolonia (CRUSELLES GÓMEZ, "Dinámica demográfica ...", cit., p. 39; MUELLER, Immigrazione ..., cit., pp. 18-20) o Barcelona (SOLDANI, Uomini d'affari ..., cit., pp. 133-135 y 137). 
De entrada, esos datos subrayan la limitada importancia cuantitativa de los miembros avecindados de esta corriente inmigratoria, sobre todo la procedente del norte de la península italiana. Sirvan unas cifras. Entre 1475 y 1500 se ha localizado la presencia en la capital valenciana de 557 ligures, toscanos, vénetos y lombardos, entre comerciantes, artesanos y otros agentes. Alrededor de un centenar vivió en el territorio, de manera más o menos permanente, un período superior a los veinte años. Pero sólo 17 gestionaron su avecindamiento durante las fechas indicadas, o antes y después de ellas. Y de esos 17, los porcentajes de domiciliación legal con respecto al colectivo de los desplazados fueron, por sectores, mayores entre los artesanos y los corredores que entre los mercaderes, porque entre éstos últimos (que suman en el censo investigado un total de 424 individuos) únicamente hubo 8 avecindados. Aparte, esta misma muestra ilustra que el acto podía realizarse en instantes cercanos al inicio de la residencia del operador en la ciudad (como comienzo de su incorporación a la sociedad nativa) o tras mucho tiempo en ella (tal vez como culminación de las tareas desempeñadas desde antiguo en la región $)^{51}$. Cosas distintas son, como señalan también este sondeo y otros del $\mathrm{XV}$, que la inserción entre los autóctonos acabara fracasando, o que las diversas fuentes que testimonian la vida de los afectados les confieran en ocasiones ascendencias y nacionalidades diferentes, incluso a pesar de la existencia de procesos de avecindamiento. Según los casos, estas situaciones serían interpretables como meros errores documentales o, lo que es más significativo, como el mantenimiento de una confusión de domicilios, la instauración de una auténtica doble ciudadanía, o el aprovechamiento de una especie de juego en la atribución de los orígenes en función de determinados intereses, coyunturales o estructurales ${ }^{52}$.

51 IGUAL LUIS, Valencia e Italia ..., cit., pp. 219-220 y 232. En esta misma referencia puede comprobarse que, durante todo el siglo XV a partir de 1410 , el total de los italianos avecindados en Valencia sumó sólo 37. Pero es posible que la cifra real de los avecindamientos italianos desbordara este número, porque la propia documentación dificulta en ocasiones identificar como tales italianos a algunos de los nuevos ciudadanos (CRUSELLES GÓMEZ, Los comerciantes valencianos ..., cit., p. 74). Aun así, como subraya también esta última cita, en ningún caso parece que la opción del avecindamiento fuera usual entre dichos italianos, sobre todo los mercaderes.

52 CRUSELLES GÓMEZ, Los mercaderes de Valencia ..., cit., pp. 66 y 71; IGUAL LUIS, Valencia e Italia ..., cit., pp. 138-139. No es descartable que la fluctuación en la asignación de orígenes pudiera ser el fruto también de una diferencia entre el lugar de procedencia efectiva del inmigrante y la vecindad oficial que ostentaba antes de llegar a Valencia, entre otras cosas porque no son infrecuentes los casos en que el desplazamiento al Mediterráneo ibérico era posterior a otros movimientos geográficos previos (CRUSELLES GÓMEZ, Los mercaderes de Valencia ..., cit., p. 72; SOLDANI, Uomini 
La utilización de dicho juego frente a los recaudadores fiscales era algo muy típico entre los comerciantes, que solían perseguir las mayores posibilidades de exención (legales o ilegales) para sus tráficos. Contra ello previenen continuamente en sus variadas formas las autoridades valencianas de la época. Pero este hecho, el juego citado, adquiere un relieve distinto cuando aparece reiterado en un único personaje y en episodios heterogéneos. En ese sentido, por ejemplo, el milanés Franco Serraineri se movió por los mercados de Valencia hacia 1396-1415 como negociador veneciano. Sin embargo, disponía desde el mismo 1396 de la vecindad oficial valenciana, que tuvo que repetir ante el municipio dos veces más en 1401 y $1403^{53}$. Los intentos de esquivar contextos discriminatorios y alguna amenaza de destierro radicarían probablemente en la base de estas oscilaciones de Serraineri. Y lógicas similares, de modo todavía más acentuado, debieron darse también con el mercader florentino Amoreto di Donino, que habitó en Valencia entre las décadas 1420 y $1470^{54}$.

Para oponerse a una expulsión de los florentinos de la Corona de Aragón decretada por el monarca en 1447, Donino argumentó que sus padres eran en realidad lombardos y que él había nacido en la población también lombarda de Pavía. De aquí había marchado a Pisa y Florencia, donde residió tres años antes de venir a Valencia. Ya fuera porque los oficiales reales de esta última capital admitieron las alegaciones de Donino, ya fuera porque pesó en ellos el realce de las actividades económicas y de los lazos personales del florentino en el territorio ${ }^{55}$, o ya fuera por todo junto, la verdad es que nuestro mercader parece eludir el exilio mencionado. En principio, esto no supondría más problemas salvo por tres detalles: uno, que es posible que Amoreto di Donino perteneciera no a ninguna familia lombarda, sino a un célebre linaje toscano

d'affari ..., cit., p. 41).

53 MAINONI, P., Mercanti lombardi tra Barcellona e Valenza nel Basso Medioevo, Bolonia, 1982, pp. 19-20; CRUSELLES GÓMEZ, Los mercaderes de Valencia ..., cit., p. 70.

54 Las principales informaciones sobre la vida valenciana de Donino constan en IGUAL LUIS, Valencia e Italia ..., cit., pp. 231-232, e ÍDEM, "La ciudad de Valencia y los toscanos en el Mediterráneo del siglo XV", en Revista d'Història Medieval, 6, Valencia 1995, pp. 94-95.

55 Sobre sus actividades económicas, aparte de los tráficos comerciales en la propia ciudad de Valencia, Donino mantuvo también fuertes intereses mercantiles y rentistas en la zona de Alicante (SOLER MILLA, J.L., "Economía agraria y mercantil de las aljamas valencianas. El ejemplo de Novelda (siglo XV)", en POVEDA NAVARRO, A. - SOLER MILLA, J.L. (coords.), Historia y arqueología de Sharq al-Andalus, Alicante, en prensa), así como ramificaciones hacia Barcelona (SOLDANI, Uomini d'affari ..., cit., p. 395). Sobre los lazos personales de Donino en Valencia cabe resaltar que, en fechas desconocidas y tras haberse casado primero aquí con una joven florentina, se unió después a Damiata de Vic, hija del caballero Galceran de Vic. 
de la Baja Edad Media (los Mannelli); dos, que el propio Donino se había avecindado en 1427 por diez años en Valencia, y en ese momento no había tenido reparos en identificarse ante las autoridades autóctonas como florentino; y tres, que tampoco en 1475 , al redactar su testamento, tuvo escrúpulos a la hora de registrarse notarialmente como mercader de nació florentina, però de molts anys ençà ciutadà de València.

En hipótesis, y en relación con la expulsión de 1447, cabe pensar que Donino empleó datos espurios para evitarla y que, quizá, contó para ello con el apoyo más o menos tácito de las clases dirigentes valencianas ${ }^{56}$. Pero la variación de calificaciones nacionales o de origen a lo largo de su carrera demostraría a otro nivel, como sucedía también con Franco Serraineri y con bastantes casos más, el uso que se hacía de las mismas como nociones negociables en cronologías y circunstancias determinadas, según me he atrevido a definir en páginas anteriores. De todas formas, la comparación que vengo manteniendo entre los avecindamientos y las restantes fuentes acreditativas de las trayectorias de los inmigrantes en Valencia aún aporta un último factor de importancia. Es el hecho de que hubo mercaderes foráneos que no legalizaron jamás su vecindad en la capital, aunque llevaran en ella muchos años y aunque la propia documentación les abriera las puertas para reputarlos como valencianos a todos los efectos. Es decir: que hubo comerciantes extranjeros a los que llegó a conocerse como ciudadanos locales, sin que mediara instrumento certificatorio de los poderes institucionalizados.

En esta ocasión, tal comportamiento es atestiguable tanto entre los operadores italianos de la Valencia cuatrocentista, como en otros grupos coetáneos de negociadores no nacidos en la ciudad ${ }^{57}$. Con independencia de las razones que justificaran esta situación en cada agente, la extensión del fenómeno probaría no sólo que no hubo un control administrativo riguroso sobre los procesos de naturalización, sino que tampoco el avecindamiento era un acto necesariamente obligado para ello. Así, aunque el recurso a las instituciones públicas podía resultar conveniente a veces para lograr el grado de ciudadanía, parece que en Valencia se ofrecían vías alternativas para suplir el registro

56 Este apoyo, general hacia los toscanos, está demostrado en Valencia con las apelaciones que se hicieron desde las autoridades regnícolas a la benevolencia del soberano a la hora de aplicar el destierro de los florentinos (IGUAL LUIS, Valencia e Italia ..., cit., p. 60; ÍDEM, "La ciudad de Valencia ...", cit., p. 86). Aparte, también en Barcelona se ha detectado entonces la intercesión del municipio para evitar la expulsión de algunos florentinos, bien radicados en la capital catalana (SOLDANI, Uomini d'affari ..., cit., pp. 136-137).

57 IGUAL LUIS, Valencia e Italia ..., cit., pp. 220 y 273; CRUSELLES GÓMEZ, Los mercaderes de Valencia ..., cit., pp. 61-75; ÍDEM, Los comerciantes valencianos ..., cit., pp. 74-75. 
oficial. Vías que, por ejemplo, pasaban porque los mercaderes extranjeros se insertaran en las redes de la sociabilidad urbana a través de mecanismos como la residencia prolongada, el nexo matrimonial con familias autóctonas, el acceso a propiedades inmuebles y, por supuesto, el engarce de numerosos elementos personales, económicos y empresariales de colaboración con los operadores locales $^{58}$. Al final, y a no ser que estas ideas deriven de un defecto de investigación o de conservación de fuentes, sí debió existir un camino llamémosle social de valencianización práctica.

Una primera consecuencia de este escenario iría en línea semejante a determinados argumentos que se han señalado para la Italia de inicios de la Modernidad $^{59}$. Aquí, como en Valencia, la posibilidad que hallaron los agentes foráneos de conducir sus negocios y sus vidas infiltrándose en los intersticios del sistema convierte en un problema ficticio, hasta cierto punto, la concesión de la ciudadanía como requisito ineludible (o muy pertinente) para el desarrollo de las actividades. De hecho, el hiato entre las circunstancias formalesinstitucionales (de las normas legales y las barreras discriminatorias hacia los extranjeros) y la realidad sobre el terreno (del desenvolvimiento concreto del comercio y de las oportunidades reales que autóctonos e inmigrantes tenían de vertebrarlo) hace comprensible que no todos los mercaderes arribados de otras partes vieran imprescindible solicitar la vecindad oficial.

Una segunda consecuencia de lo indicado sería la ratificación de esa permeabilidad que he escrito al comienzo del apartado, como característica en principio de las relaciones de Valencia con los extranjeros. Siempre durante el XV, los movimientos valencianos de gentes castellanas ${ }^{60}$ y de comerciantes alemanes y franceses ${ }^{61}$ diseñan panoramas de gran normalidad en el despliegue cotidiano de los vínculos socioeconómicos: había abundantes espacios y herramientas de cooperación y alianza con los nativos y con otros inmigrantes, se cerraban infinidad de negocios en múltiples direcciones y

58 CRUSELLES GÓMEZ, "Dinámica demográfica ...", cit., p. 44; ÍDEM, Los comerciantes valencianos ..., cit., pp. 74-77.

59 FUSARO, "Gli uomini d'affari ...", cit., p. 377.

60 CRUSELLES GÓMEZ, E., "Mercaderes castellanos en Valencia (1400-1450)", y NAVARRO ESPINACH, G., "Emigrantes castellanos en la sedería de Valencia (1479-1524)", en XV Congreso de Historia de la Corona de Aragón (celebrado en Jaca, 20-25 de septiembre de 1993), tomo II: Relaciones de la Corona de Aragón con los estados cristianos peninsulares (Siglos XIII-XV), Zaragoza, 1997, pp. 84-99 y 249-267, respectivamente.

61 HINOJOSA MONTALVO, J., "Mercaderes alemanes en la Valencia del siglo XV: la 'Gran Compañía' de Ravensburg", en Anuario de Estudios Medievales, 17/1, Barcelona 1987, pp. 455-468; CRUSELLES GÓMEZ, E., "El mercado de telas y 'nuevos paños ligeros' en Valencia a finales del siglo XV", en Acta Historica et Archaeologica Mediaevalia, 19, Barcelona 1998, pp. 245-272; IGUAL LUIS, Valencia e Italia ..., cit., pássim. 
con la intervención de sujetos de diversos orígenes, y se verificó una intensa capilaridad en la penetración territorial de los foráneos en el reino. Son panoramas, en definitiva, que confirman lo que ya he comentado también en un momento anterior del artículo: que, para ciertos mercaderes, la noción de extranjería llegaba a diluirse notablemente en bastantes eventos de la vida diaria. Sin embargo, vuelve a ser entre los operadores italianos de Valencia donde se encuentran algunos de los mejores modelos de tales dinámicas, que son entonces comparables además con lo ocurrido con los mismos italianos en otras ciudades y regiones hispánicas y, especialmente, en Cataluña ${ }^{62}$.

En general, es verdad que la inmensa mayoría de estos agentes acudía por pocos años a las plazas ibéricas y no estabilizaba en ellas su domicilio. Pero, centrándonos ya en lo que dejan vislumbrar los análisis valenciano y catalán del Cuatrocientos, una minoría muy trascendente sí permaneció largo tiempo y manifestó una aguda voluntad de integrarse en los distintos mecanismos sociales, económicos y hasta políticos de funcionamiento local. Incluso, varios casos extremos (y, por eso, aún más minoritarios y significativos) dibujan biografías atrayentes, a nivel individual o en el curso de las generaciones familiares: las que consentían que algunos de los italianos y/o sus parentelas pasaran del estatus de mercader o financiero extranjero al de caballero o, por lo menos, al de personajes conectados con señoríos y derechos jurisdiccionales, y que lo hicieran combinando simultánea o sucesivamente un amplio abanico de tratos emprendedores y rentistas, la ocasional participación en determinadas instancias de la política municipal y estatal, y el tejido de afinidades plurales con las sociedades valenciana y catalana, aunque en particular con sus sectores de élite $e^{63}$.

En muchas oportunidades, y salvando como siempre la especificidad de cada itinerario singular, parece que estas trayectorias de los mercaderes italianos en la Corona de Aragón se asentaban sobre dos cimientos: la puesta en marcha del sinfín ya reiterado de colaboraciones empresariales y comerciales con los negociadores autóctonos, y el mantenimiento de redes consis-

62 Para la comparación con el ejemplo catalán, véanse los recientes trabajos de Maria Elisa Soldani, tanto su libro Uomini d'affari ..., cit., como los artículos que reseñaré en las notas inmediatamente posteriores. Acerca de las situaciones de otros territorios hispánicos, IGUAL LUIS, "Banqueros y comerciantes ...", cit., pp. 167-179.

63 IGUAL LUIS, Valencia e Italia ..., cit., pp. 224-225, 232-239 y 430-431; SOLDANI, M.E., "A Firenze mercanti, cavalieri nella signoria dei re d'Aragona. I Tecchini-Taquí tra XIV e XV secolo", en Anuario de Estudios Medievales, 39/2, Barcelona 2009, pp. 576, 596, 597, 598 y 603; EADEM, "Da Accettanti a Setantí: il processo di integrazione di una famiglia lucchese nella società barcellonese del Quattrocento", en IANNELLA, C. (a cura di), Per Marco Tangheroni. Studi su Pisa e sul Mediterraneo medievale offerti dai suoi ultimi allievi, Pisa, 2006, p. 233. 
tentes de vinculación con los propios compatriotas, mediante instrumentos formales (las compañías mercantiles) e informales (los lazos de confianza y amistad). Luego, y gracias al desarrollo de una estancia dilatada, dichos fundamentos eran ampliables con la planificación de pactos matrimoniales internos o externos a la comunidad extranjera original, con la compra y conservación de importantes posesiones rústicas y urbanas, con los servicios prestados a la monarquía y los municipios y, como expresión culminante excepcional, con la adopción de rasgos nobiliarios de vida y recursos. El final de este tipo de recorridos, terciara o no con antelación un documento oficial de avecindamiento, solía conllevar la relegación de la auténtica procedencia del individuo o la familia afectados, su mezcla completa con el entramado local y, a la postre, la catalanización lingüística de sus nombres y apellidos. A lo largo de la última centuria medieval, es lo que acontece con sus correspondientes matices tanto con los toscanos Accettanti y Tecchini en el área catalana, como con el sienés Pietro Spannochi, el pisano Giovanni dell'Agnello y el genovés Francesco Palomar en Valencia ${ }^{64}$.

\section{DE LAS LÓGICAS DE ENFRENTAMIENTO A LA ORGANIZACIÓN DE LOS INMIGRANTES}

Evoluciones como las que acabo de exponer enfatizan que los grados de especialización profesional de los inmigrantes y de negociación socioeconómica con los estamentos dominantes autóctonos facilitaban la promoción y el ascenso de los primeros en las jerarquías de prestigio. Así, queda ilustrado cómo la movilidad geográfica y la movilidad social podían llegar a estar íntimamente relacionadas en las postrimerías del Medievo ${ }^{65}$. Pero dichas evoluciones contribuyen asimismo a subrayar una lectura benévola

64 Las trayectorias de los toscanos citados de Cataluña figuran en SOLDANI, "A Firenze mercanti ...", cit., pp. 575-604, en especial pp. 576, 581, 583 y 603-604, y en EADEM, "Da Accettanti ...", cit., pp. 209-233. Más en general, véase también EADEM, "Alleanze matrimoniali e strategie patrimoniali nella Barcellona del XV secolo: i mercanti toscani fra integrazione e consolidamento della ricchezza", en Archivio Storico Italiano, CLXII/602, Florencia 2004, pp. 667-696. El detalle de los italianos de Valencia (Spannochi, dell'Agnello y Palomar) consta en IGUAL LUIS, D., "Sieneses en la Valencia bajomedieval: los Spannochi y sus representantes empresariales", en ASCHERI, M. NEVOLA, F. (a cura di), L'ultimo secolo della Repubblica di Siena. Politica e istituzioni, economia e società, Siena, 2007, pp. 333-360; ÍDEM, "Familia y escalas económicas en el comercio medieval: el caso de Giovanni dell'Agnello, mercader pisano de Valencia (1472-1501)", en Homenatge a Maria Teresa Ferrer i Mallol, Barcelona, en prensa; e ÍDEM, "Valencia y Sevilla en el sistema económico genovés de finales del siglo XV", en Revista d'Història Medieval, 3, Valencia 1992, pp. 106-108.

65 SOLDANI, "A Firenze mercanti ...", cit., p. 604; EADEM, Uomini d'affari ..., cit., p. 569. 
de la presencia mercantil extranjera en la Valencia de la época. Una lectura que, si se me permite aludir al título del artículo, rememoría la idea de los comerciantes como "igualadores del mundo" y que, desde luego, valoraría favorablemente la posición de los inmigrantes (de algunos de ellos, al menos) por lo que aportaban entonces al dinamismo y la proyección de la sociedad y la economía valencianas. No se olvide que la propia documentación local introducía a veces también, de modo más o menos explícito, esta percepción positiva del significado de la acción foránea.

No obstante, habría que ir con cuidado para no dejarse llevar, ni tan siquiera en la Valencia de los siglos XIV y XV, por visiones demasiado idílicas del resultado de la confrontación entre autóctonos e inmigrantes. Si seguimos recordando los apuntes que he reproducido al inicio del texto sobre la diversa concepción del comercio y los extranjeros, es notoria la existencia de fuentes que proporcionan imágenes contrarias. Esas otras fuentes insisten tanto en los efectos perversos que tenía la actividad de los foráneos, sobre todo en relación con las posibilidades de promoción de los protagonistas nativos del mercado, como en la implantación del fenómeno de la extranjería como hecho de antagonismo, de presión y represión y de discriminación. Las causas que animaban la emergencia de estas realidades eran varias. Pero, en síntesis, creo que son agrupables en torno a tres grandes lógicas que, en Valencia como en otros lugares, no siempre se concretaron completamente por separado, ya que las propias coyunturas históricas las hicieron caminar absoluta o parcialmente juntas ${ }^{66}$.

Una primera lógica se producía cuando se abrían conflictos diplomáticos y/o militares entre territorios y poderes. Conflictos que podían venir desencadenados justo por factores económicos, aunque solían utilizar en cualquier caso al comercio bilateral y a los mercaderes de los países en guerra como marco de represalias, de expulsiones, de imposición fiscal o de salvoconductos y guiajes. Esto supone incardinar nuestra problemática en el conjunto de vínculos entre estados diferentes, y asumir que el comercio fue no sólo un instrumento económico, sino también una eficaz arma política e ideológica al servicio de los citados poderes.

Ambos elementos se han apreciado ya desde 1300, con mayor o menor exhaustividad, en los enlaces de Valencia con Castilla y con Italia, por ejem-

66 Compruébese la justificación general de las tres lógicas que voy a pasar a comentar, no sólo en Valencia, en CARRÈRE, Barcelona ..., cit., p. 22; IGUAL LUIS, "Banqueros y comerciantes ...", cit., pp. 170-173; ÍDEM, "Política y economía ...", cit., pp. 260-268; e IRADIEL, P., "Nápoles en el mercado mediterráneo de la Corona de Aragón", en GALASSO, G. - HERNANDO SÁNCHEZ, C.J. (eds.), El reino de Nápoles y la monarquía de España. Entre agregación y conquista (1485-1535), Madrid, 2004, pp. 265-275. 
plo $^{67}$. A través de la oportuna seriación cronológica y factual, que no cabe detallar aquí, se hace patente la frecuencia con que las relaciones con los dos espacios se vieron salpicadas por disputas políticas o armadas que conllevaron rupturas de los contactos pacíficos, por obstáculos a la circulación de personas y productos, por secuestros de los bienes valencianos de comerciantes castellanos e italianos ${ }^{68}$, por aumentos arancelarios y, cómo no, por el destierro de los tratantes extranjeros. Incluso, durante un conflicto interno a la Corona de Aragón como fue la guerra civil catalana de 1462-1472, se reprodujeron en Valencia situaciones asimilables: se ordenó el embargo de las posesiones de los catalanes rebeldes a la monarquía y la recaudación de un dret de peatge dels catalans ${ }^{69}$. En otras ocasiones, sin embargo, incidentes más puntuales (como un asalto marítimo o un robo pirático) provocaron episodios de represalia o marca sobre determinados tráficos, que desembocaron en auténticos impuestos cobrados a operadores de procedencias como la francesa (hacia 1350), la portuguesa (desde 1464) o la genovesa (entre 1507 y 1509$)^{70}$.

Son imaginables las alteraciones del movimiento comercial que generaban los acontecimientos de este tipo, aunque no siempre lo hacían con la misma intensidad ni la misma gravedad. De hecho, por lo que toca a las expulsiones de mercaderes foráneos, convendría evaluar bien en cada caso su efectividad

67 Para Castilla, revísese por ejemplo FERRER MALLOL, M.T., Entre la paz y la guerra. La Corona catalano-aragonesa y Castilla en la Baja Edad Media, Barcelona, 2005. Para Italia, IGUAL LUIS, Valencia e Italia ..., cit., particularmente pp. 31-117.

68 Como se observa también gracias a algunos estudios específicos: CABANES CATALÁ, M.L., "Secuelas de la guerra entre Castilla y Aragón: confiscaciones de bienes a mercaderes castellanos", en Homenaje al Dr. D. Juan Reglà Campistol, vol. I, Valencia, 1975, pp. 148-153, o CARIÑENA BALAGUER, R. - DÍAZ BORRÁS, A., "La colonia genovesa en Valencia durante la guerra civil catalana: el secuestro de sus bienes en 1472", en Anuario de Estudios Medievales, 24, Barcelona 1994, pp. 131-154.

69 AURA GÓMEZ, A., "Los mercaderes catalanes en la ciudad de Valencia durante la Guerra Civil del Principado", en NARBONA VIZCAÍNO, R. (a cura de), XVIII Congrés Internacional d'Història de la Corona d'Aragó (celebrado en Valencia, 9-14 de septiembre de 2004), vol. I, Valencia, 2005, pp. 1120-1121. La orden de embargo, emitida por el rey Juan II en 1462, fue rechazada por las autoridades municipales de Valencia a causa del daño que acarrearía en los intereses comerciales y fiscales propios. Por eso fue finalmente revocada. El dret de peatge dels catalans, por su parte, fue creado asimismo por el soberano en 1463.

70 DÍAZ BORRÁS, A., "Marca, arte de la mercadería y protorganización de la estructura recaudatoria en la Valencia del Trescientos", en Anuario de Estudios Medievales, 41/1, Barcelona 2011, pp. 3-29 (para la represalia sobre operadores franceses); MUÑOZ POMER, M.R. - NAVARRO ESPINACH, G., "Los mercaderes y la fiscalidad: el dret dels portuguesos en Valencia (1464-1512)", en ADÃO DA FONSECA, L. - CADEDDU, M.E. (a cura di), Portogallo mediterraneo, Cagliari, 2001, pp. 195-257 (sobre portugueses); IGUAL LUIS, Valencia e Italia ..., cit., pp. 173-174 (sobre genoveses). 
real. Pero ya no sólo porque había estrategias que posibilitaban escapar a la deportación, o como mínimo resistirse a ella, como se ha visto en el exilio florentino promulgado en 1447. También porque los edictos de expatriación podían considerar excepciones de importancia. Basta contemplar en 1451 una nueva expulsión de la Corona de Aragón de los florentinos que, como se recalca desde la documentación valenciana, no afectaba a los sujetos de ese origen que estaban casados o tenían hijos en Valencia y habían mostrado su propósito de no regresar a Italia, aunque esto únicamente sería así si tales personas no negociaban en representación de otros florentinos que incumplieran el requisito indicado (la contínua habitació ab lurs mullers en la Corona). Y algo igual se estipulaba para los pisanos, que entonces eran súbditos de Florencia, pero que se librarían de la marcha si no conservaban vínculos con Pisa y Florencia y no actuaban por florentinos, sino que lo hacían en nombre propio o en el de extranjeros no vetados ${ }^{71}$. A pesar de todo hay que reconocer que, precisamente estas medidas mencionadas de 1447 y 1451, parecen encontrarse entre las que tuvieron mayor éxito a lo largo del siglo XV. Adoptadas en el contexto de la política mediterránea de Alfonso V el Magnánimo, supusieron un duro golpe para la posición económica de los florentinos en tierras aragonesas y hasta promovieron su relativa sustitución por otros grupos emprendedores, especialmente en el entorno financiero de la casa real ${ }^{72}$.

La segunda lógica que hacía aflorar lo foráneo como factor de antagonismo tenía que ver con la fiscalidad. La cuestión impositiva, claramente relacionada con lo anterior, incumbió también obviamente durante la Baja Edad Media a la necesidad de recursos que experimentaron los poderes. Además, al recaer sobre el comercio bastantes de los esfuerzos arancelarios del período, este asunto fue una herramienta preferente a la hora de adoptar orientaciones político-mercantiles de libre competencia o de proteccionismo en el contraste entre autóctonos y extranjeros. Una situación acentuada desde el instante en que, justamente, la procedencia de los individuos y su ciudadanía o vecindad legales eran claves en la construcción del sistema tarifario, puesto que daban pie a obligaciones o privilegios de diferente signo.

71 Archivo del Reino de Valencia (en adelante, ARV), Bailía, Lletres i Privilegis, $\mathrm{n}^{\circ} 1151$, ff. 327v-328r (1451-X-16).

72 IGUAL LUIS, Valencia e Italia ..., cit., p. 60; ÍDEM, "Entre Valencia y Nápoles. Banca y hombres de negocios desde el reinado de Alfonso el Magnánimo", en En la España medieval, 24, Madrid 2001, pp. 114-115; SOLDANI, Uomini d'affari ..., cit., p. 572. Véase también SOLDANI, M.E., "Alfonso il Magnanimo in Italia: pacificatore o crudel tiranno? Dinamiche politico-economiche e organizzazione del consenso nella prima fase della guerra con Firenze (1447-1448)", en Archivio Storico Italiano, CLXV/612, Florencia 2007, pp. 266-324. 
Ya desde el Doscientos valenciano, y aparte de la exención de algunos impuestos comerciales de la que gozaban los habitantes de la capital, no faltaron las franquicias otorgadas por la monarquía a gentes de otras localidades del reino ${ }^{73}$. Incluso, probablemente a finales del mismo siglo XIII o ya en el XIV, en la colecta de una de las tasas más importantes sobre los intercambios en el territorio (la lezda de Tortosa), se alcanzó un estadio de cierta complejidad al establecerse diversas categorías de exoneración o de pago, según el origen de los contribuyentes ${ }^{74}$. No obstante, quizá la muestra máxima de lo básica que fue la ascendencia personal para la fiscalidad mercantil se dio con la creación, en el XIV y aún más en el XV, de derechos que recaían esencialmente sobre "hombres extraños al reino", por repetir el vocabulario foral. Eran derechos, aplicados también en su mayoría en el resto de la Corona de Aragón, que gravaban el comercio con determinados países (como la "quema" respecto a Castilla, desde 1329), o que repercutían de forma directa sobre las operaciones de negociadores extranjeros: desde inicios del Cuatrocientos, sobre los alemanes y saboyanos (1420), los portugueses (1464), los genoveses (1484) y los genéricamente "italianos", con quienes se aludía en el primer momento de fundación de la tasa (1403) a florentinos, luqueses, sieneses y otros toscanos y a todos los lombardos, piamonteses, romañoles, marquesanos $e$ altres ytalians ${ }^{75}$.

73 IGUAL LUIS, D., "Leconomia comercial i marítima de València durant el regnat de Jaume I", en Congrés Internacional "Jaume I: La conquesta i l'organització de Mallorca. L'economia comercial i marítima de les terres de parla catalana durant el regnat de Jaume I" (celebrado en Palma de Mallorca, 13-15 de octubre de 2008), en prensa.

74 La clasificación figura en una lista reproducida entre dos documentos de 1298 y 1399 , y quizá tendría como fechas máximas las de alrededor de 1310-1320 (por la mención que todavía se hace en el elenco a la "tierra del Temple", orden que fue disuelta en la Corona de Aragón justo en torno a ese período, como es bien sabido). Sea como fuere, en la nómina se reseñan hasta cinco clases de personas, según su posición ante la lezda tortosina. 1) Los que tenían la exención total (quienes eran de Génova, Pisa, Alicante, Narbona, Zaragoza, Gerona, Orihuela, Elche, Guardamar, Puzol, Castellón y Tarragona, entre otros); 2) Los que tenían la exención de 1/3 (quienes eran de Mallorca y las islas, Colliure, Palamós, Barcelona, Cervera de Urgel, Lérida, Calatayud, Daroca, Huesca, Teruel, Valencia, Alcira, Játiva, Sagunto, Burriana, Morella, Caspe y Alcañiz, menos sus aldeas, entre otros); 3) Los que tenían la exención de dos partes (quienes eran de la tierra del Temple, Cervera y San Mateo); 4) Los que tenían la exención de la mitad (quienes eran de Mequinenza y de la tierra del Hospital, excepto Cervera y San Mateo); 5) Los que no tenían ninguna exención (los hombres de Montpellier, Perpiñán, Puigcerdá, Cadaqués, Blanes, Tárrega y las aldeas de Alcañiz, entre otros). Véase ARV, Real Cancillería, $\mathrm{n}^{\circ} 687$, ff. 138v-140r.

75 Para no inflar más el aparato bibliográfico, sobre los derechos mencionados remito a IGUAL LUIS, Valencia e Italia ..., cit., pp. 121-187. Sólo acerca de la "quema" añado DIAGO HERNANDO, M., "La 'quema'. Trayectoria histórica de un impuesto sobre los flujos comerciales entre las coronas de Castilla y Aragón", en Anuario de Estudios 
La tercera y última lógica que motivaba que la extranjería fuera un elemento de enfrentamiento en la sociedad valenciana se planteaba cuando las clases mercantiles locales adquirían una cierta conciencia de inferioridad técnica y comercial en comparación con otros grupos de tratantes y, por tanto, consideraban que la competencia de éstos les perjudicaba en gran medida. Era éste un debate más estrictamente económico, que acostumbraba a enlazar con las circunstancias de complementariedad o no de los intercambios entre distintas regiones y, sobre todo, con la posición de superioridad o subordinación empresarial y financiera que unos mundos mercantiles podían mantener con respecto a otros. Y desde luego, las realidades derivadas de ello se agravaban si los comerciantes castigados por los rangos de sometimiento eran los naturales de los países ibéricos de la Corona de Aragón.

La experiencia y la habilidad negociadoras de dichos comerciantes naturales no dejó de ser reconocida, en la época, por algunos de los agentes extranjeros que rivalizaban con ellos ${ }^{76}$. Sin embargo, por mucho que esto pudiera ser verdad, la documentación también hace constar en ocasiones comparaciones de capacidades entre grupos emprendedores, en las que los autóctonos no solían salir bien parados. Observando estas comparaciones, cabe recelar de si retrataban situaciones demostrables con plenitud o si, por el contrario, respondían a meros argumentos interesados y manipulados ${ }^{77}$. Pero de lo que no hay duda es de que tales opiniones sí subrayaban por lo menos, de manera estructural o coyuntural, la percepción de determinadas condiciones de desventaja en las que cayeron los profesionales nativos.

Significativamente, algunas dinámicas de este tenor surgieron en medio de la misma dialéctica entre los colectivos propios de la Corona. Los responsables municipales de Valencia, hablando en 1335 del abastecimiento cárnico de la ciudad, testimoniaban la imposibilidad de proveerse de carne en Aragón, puesto que los carniceros de Cataluña se llevaban buena parte

Medievales, 30/1, Barcelona 2000, pp. 91-156. El impuesto de los portugueses surgió a consecuencia de la marca justificada supra, en la nota 70. A las tasas indicadas habría que sumar, aunque con otros matices en su significado, el dret de peatge dels catalans ya reseñado y ciertas cargas que pesaban sobre los judíos y los musulmanes que no eran del reino de Valencia (GUIRAL, J., "Les relacions comercials del regne de València amb Berberia al segle XV", en FURIÓ, A. (ed.), València, un mercat medieval, Valencia, 1985, p. 280).

76 Por ejemplo, en relación sobre todo con los mercaderes catalanes, por los negociadores toscanos vinculados al círculo empresarial datiniano, según consta en documentos de 1396 y 1397 (CARRÈRE, Barcelona ..., cit., p. 34; EADEM, Barcelona 1380-1462. Un centre econòmic en època de crisi, vol. II, Barcelona, 1978, p. 66; SOLDANI, Uomini d'affari ..., cit., p. 575).

77 Así se apunta también desde Barcelona en SOLDANI, Uomini d'affari ..., cit., pp. 574575. 
de los ganados de allí per lo major for que venen ${ }^{78}$. No obstante, las mejores muestras de este género de confrontaciones se dieron por iniciativa local con mercaderes extrapeninsulares. Por ejemplo, en la Valencia de finales del siglo $\mathrm{XV}$, con ciertas empresas alemanas a las que se opusieron los tenderos urbanos por las prácticas de venta al detalle de telas ${ }^{79}$. También por ejemplo, en general en el Oriente peninsular aragonés, con unos operadores italianos que, como se habrá notado ya por algunas palabras que he escrito al principio del artículo, encarnaron desde el XIII el modelo de mercader potente por excelencia y cuya actuación llegó a estimarse limitadora o menoscabadora del éxito económico de los autóctonos.

Si hacemos caso de lo que afirmaban en 1399 los jurados de la capital valenciana, en referencia a ytalians e venecians, la gran potència de lur mercaderia les permitía adelantarse en los negocios y dominarlos por completo, tanto dentro del reino como hacia Castilla. Ello iba en detrimento de unos mercaderes valencianos que, como no tenían capitales abundantes, no estaban en disposición de efectuar gran o poderosa mercaderia ${ }^{80}$. Por esos mismos años del tránsito entre el XIV y el XV, la aparente superioridad competitiva de estos foráneos sobre el territorio, en especial a través del paradigma toscano, se trasluciría también en las técnicas de negociación y organización societaria con que operaban, en las numerosas vías de comunicación e información que empleaban, en las importantes cifras de productos que manejaban, y en su capacidad de adaptarse a las variaciones de la oferta y la demanda y hasta de influir en ellas ${ }^{81}$. La dificultad que los agentes locales podían sentir para equipararse con estas características hacía que muchos se consideraran excluidos de ámbitos comerciales donde se amasaban grandes beneficios y que, por tanto, vieran coartados sus anhelos de progreso.

Por lo que apuntan las noticias valencianas y catalanas del Bajo Medievo, las antipatías despertadas por situaciones como éstas llegaban a desembocar en enemistades o querellas más o menos palpables contra los italianos, fundamentalmente cuando se verificaban dos condiciones juntas o por separado: una, si se definían problemas comerciales que obstaculizaban las oportuni-

78 RUBIO VELA, A., "Don Juan Manuel, Valencia y el comercio con Castilla en la primera mitad del siglo XIV", en Boletín de la Sociedad Castellonense de Cultura, 63/3, Castellón 1987, p. 400.

79 IGUAL LUIS, "Política y economía ...", cit., pp. 266-267.

80 RUBIO VELA, A. (ed.), Epistolari de la València medieval, Valencia, 1985, pp. 142-143.

81 ORLANDI, A., "Estudi introductori", en EADEM (a cura d'), Mercaderies i diners: la correspondència datiniana entre València i Mallorca (1395-1398), Valencia, 2008, pp. 44 y 47; EADEM, "Un pratese nel Maestrazgo. Tuccio di Gennaio, commerciante di lana", en NIGRO, G. (a cura di), Francesco di Marco Datini. Luomo il mercante, Florencia, 2010, pp. 391-393. 
dades globales de enriquecimiento; dos, si los tratantes autóctonos ganaban conciencia de su vigor y aspiraban a eliminar del mercado a sus hipotéticos antagonistas $^{82}$. Por esto último, restringiéndonos a Valencia, hay que esperar al período posterior al final del Trescientos para apreciar los roces mayores y más graves al respecto, cuando el florecimiento de los estratos mercantiles locales ya estaba bien acreditado. Estos brotes de hostilidad hacia los extranjeros nacían de la órbita económica, aunque casi siempre acababan desparramándose nuevamente sobre la política y las opciones que las instituciones se veían obligadas entonces a escoger entre las alternativas del proteccionismo y el mercado más abierto.

A veces, a la hora de plantear tales conflictos, Valencia acompañó un movimiento extendido por los principales centros mercantiles de la Corona de Aragón: es lo que sucede en torno a 1401 frente a los florentinos y a otros italianos ${ }^{83}$, o hacia 1424 en relación general con los extranjeros ${ }^{84}$. Sin embargo, a estas oportunidades habría que añadir las que obedecieron a motivos más específicamente valencianos, como los episodios contra los negociadores genoveses que culminaron entre 1484 y 1485, si bien se arrastraban desde la década de 1470. Dichos episodios asumieron un neto componente fiscal, al concluir con un incremento de la presión arancelaria sobre los ligures. Pero, en el fondo, respondieron a un contraste de intereses interno a los grupos dominantes locales por ocupar mayores cotas de riqueza y, eso sí, captar por vía impositiva la mayor cantidad posible de recursos genoveses, justo en un momento en el que éstos estaban acudiendo profusamente al litoral regnícola y cuando la sociedad y la economía valencianas experimentaban ciertos síntomas de crisis $^{85}$.

Estos últimos acontecimientos coincidieron, siempre en Valencia, con los inicios de la institucionalización de la presencia genovesa en la ciudad. Las informaciones aisladas sobre los cónsules ligures de la capital en 1476 y

82 IGUAL LUIS, Valencia e Italia ..., cit., pp. 41-43 y 66-68; CARRÈRE, Barcelona ..., cit., II, pp. 239-249.

83 Como ya se ha citado (vease supra la nota 16 y los argumentos que justifica).

84 Un memorial dirigido al rey por las ciudades de Barcelona, Valencia, Mallorca, Tortosa, Gerona y Perpiñán se quejaba entonces de los problemas que sufría la art de la mercaderia. Y entre las soluciones que proponía estaban varias que perseguían vigilar y limitar la actividad comercial extranjera (CARRÈRE, Barcelona ..., cit., II, pp. 242 y 253-255). Pero las opiniones contrarias a los foráneos (especialmente italianos, castellanos, portugueses y alemanes), y el programa proteccionista planteado, aún eran más claros en otro memorial de 1435 que el mercader y cónsul catalán Pere d'Altelló elevó a los síndicos barceloneses que debían participar en las cortes de Monzón (ibídem, pp. 242-245 y 252-255; SOLDANI, Uomini d'affari ..., cit., pp. 299-301).

85 IGUAL LUIS, Valencia e Italia ..., cit., pp. 163-172. 
1480 y, en particular, la instauración en ella de una capilla y una cofradía de los genoveses desde 1487, permiten vislumbrar una relativa estructuración del colectivo y, también, la definición de mecanismos representativos y de defensa de posiciones ante la sociedad hospedante. Y es probable que esta defensa fuera una necesidad especialmente sentida durante esos años por los ligures, a causa del ataque impositivo que venían sufriendo y de los posibles perjuicios que éste les acarreó, sobre todo a sus niveles comerciales y artesanales más potentes. En cualquier caso, la continuidad del consulado, la capilla y la cofradía hasta los siglos modernos, cuando incluso la colonia genovesa de Valencia es citada como "nación", subraya el efecto prolongado de este proceso organizador ${ }^{86}$.

Pero, dentro de la Edad Media hasta alrededor de 1500, las formas orgánicas protagonizadas aquí por los ligures fueron similares a las concretadas por otros grupos mercantiles extranjeros. Así, aunque sea a través de referencias fragmentarias o poco claras, se conocen también los consulados que se crearon (o que se intentaron fundar) en Valencia por los castellanos (1400 y 1477), los florentinos (1429), los venecianos (1440-1504), los lombardos (1456), los franceses (1491) y los vascos $(1504)^{87}$. Aparte, con capillas propias contaron asimismo a lo largo del XV los milaneses y monferratinos y los alemanes, y hasta los mercaderes de Gerona disfrutaron de una cofradía en la ciudad entre 1368 y $1391^{88}$. En realidad, estos tipos de elementos (consulados, capillas y cofradías) fueron los únicos que consintieron, en el territorio valenciano, que los foráneos vieran reconocido cierto particularismo colectivo y que adquirieran una identidad genérica, gracias a la cual incluso los intereses de clase podían subsumirse bajo una homogénea adscripción

86 Ibídem, pp. 244-245 y 247-253; ÍDEM, "La emigración genovesa hacia el Mediterráneo bajomedieval. Algunas reflexiones a partir del caso español", en GALLINARI, L. (a cura di), Genova, una "porta" del Mediterraneo, vol. I, Génova, 2005, pp. 312 y 315. Sobre el consulado genovés de Valencia existe otra noticia aislada, anterior a las indicadas, que data de 1413.

87 FERREIRA PRIEGUE, E., "Cónsules de castellanos y cónsules de españoles en el Mediterráneo bajomedieval", en CASADO ALONSO, H. (ed.), Castilla y Europa. Comercio y mercaderes en los siglos XIV, XV y XVI, Burgos, 1995, pp. 196, 199 y 212 (sobre el consulado de los castellanos); IGUAL LUIS, Valencia e Italia ..., cit., pp. 244-245 (sobre los consulados de franceses, florentinos, lombardos y venecianos); GUIRALHADZIIOSSIF, J., Valencia, puerto mediterráneo en el siglo XV (1410-1525), Valencia, 1989 , pp. 544-545 (sobre el consulado vasco). En estas citas, y en SOLDANI, Uomini d'affari ..., cit., pp. 61-62, pueden consultarse las funciones que tenían los consulados dentro de las comunidades comerciales extranjeras del Mediterráneo.

88 IGUAL LUIS, Valencia e Italia ..., cit., p. 247; NAVARRO ESPINACH, "Los protagonistas del comercio ...", cit., p. 156. La capilla o iglesia de los alemanes se encontraba en la localidad de Puzol. 
geográfica, nacional o de orígenes. Junto a tales elementos, sólo la concesión de salvoconductos individuales y, mejor en su caso, de privilegios fiscales comunitarios fue capaz también de singularizar a los respectivos conjuntos de inmigrantes. Más allá de estas características, a fines del Medievo no se dio en Valencia nada semejante a las "naciones" mercantiles bien organizadas, reconocidas e institucionalizadas que, como sabemos, germinaron entonces en varios lugares de Europa y el Mediterráneo.

En principio, la situación valenciana de inexistencia de esas "naciones" extranjeras sería igual a la de la Barcelona coetánea. En ambos ejemplos, esta circunstancia dependería de una serie de razones específicas que, más en general, parecen diferenciar a la Corona de Aragón de otros países ${ }^{89}$. Pese a todo, por lo menos en Valencia, los datos que acabo de ofrecer enfatizan que, desde el punto de vista de la construcción de conexiones internas en los ámbitos comerciales foráneos, éstos sí dispusieron de determinados factores mínimos de organización aunque fuera de modo esporádico. Además permiten pensar que, entre algunos de los modelos que la historiografía continental ha dibujado como posibles para los asentamientos mercantiles extranjeros, los arribados a Valencia pudieron moverse entre dos extremos: quienes configuraron una natio sine natione, es decir, un grupo de ascendencia común que no originó en su seno vínculos coherentes de relieve, porque lo que predominó en él fueron los intereses individuales por encima de cualquier noción global; y quienes se desenvolvieron como una nazione che non c'è, una colonia que nunca obtuvo el reconocimiento oficial de las autoridades correspondientes, aunque llegara a desarrollar lazos internos de apoyo mutuo ${ }^{90}$.

89 Sobre el caso barcelonés y sobre las razones que diferenciaban a la Corona de Aragón en el tema de las "naciones" mercantiles, veáse SOLDANI, Uomini d'affari ..., cit., pp. 23-24 y 62-64, e IGUAL LUIS, "La emigración genovesa ...", cit., pp. 313-315. A efectos comparativos, y además de los trabajos mencionados supra en la nota 45, véanse también las siguientes obras: BASSO, E., Insediamenti e commercio nel Mediterraneo bassomedievale. I mercanti genovesi dal Mar Nero all'Atlantico, Turín, 2008; GALOPPINI, L., Mercanti toscani e Bruges nel Tardo Medioevo, Pisa, 2009; PETTI BALBI (a cura di), Comunità forestiere ..., cit., pássim.

90 La fórmula natio sine natione proviene del análisis que se hace de la presencia bajomedieval genovesa en Londres en BASSO, E., "Note sulla comunità genovese a Londra nei secc. XIII-XVI", en PETTI BALBI (a cura di), Comunità forestiere ..., cit., pp. 251 y 266-267. Y la nazione che non c'è, del examen de los alemanes en Milán y Como durante los siglos XIV-XV que consta en MAINONI, P., "La nazione che non c'è: i tedeschi a Milano e a Como fra Tre e Quattrocento", en ibídem, pp. 210-211. 


\section{AL FINAL, LECTURAS VARIADAS DE LA REALIDAD ENTRE TEN- DENCIAS GRUPALES E INDIVIDUALIDADES}

Los elementos organizativos que los mercaderes desplazados a un espacio constituían en mayor o menor medida podían ser la respuesta, como hemos visto, a algunas circunstancias de antagonismo con los autóctonos. Pero conviene recalcar que esos elementos también se ubicaban en paralelo, de una manera u otra, dentro de los mecanismos ideológicos o identitarios que ya conocemos, en los que las atribuciones nacionales servían tanto para marcar distancias con la sociedad de acogida, como para encubrir realidades diversas. Asimismo, al observar las diferencias que se daban al respecto entre ciudades y colectivos comerciales, todo ello vuelve a destacar la variedad que registraba el fenómeno a escala euromediterránea.

Manteniéndonos en esta escala, quizá un cierto apriorismo nos haría deducir que, entre los extranjeros de un origen instalados en cualquier territorio, debía ser normal el desarrollo de una genérica solidaridad interna y hasta de entidades que ayudaran a institucionalizarla, en un sentido incluso corporativo. Y ello, aunque únicamente fuera por los vínculos de múltiple significado que implicaba una procedencia compartida. No obstante, las investigaciones han trazado ya sobre este tema un panorama bastante menos unilateral, y no sólo por lo que señalan las situaciones de Valencia y Barcelona. Desde luego, las "naciones" mercantiles o los meros asentamientos de inmigrantes no actuaban siempre como estructuras monolíticas, de la misma forma que los índices de cooperación económica no se construían siempre sobre la base de las afinidades étnicas o culturales ${ }^{91}$. En esa línea habría que desmitificar también la idea de la solidaridad con la que los agentes foráneos, casi por fuerza, trabajaban y vivían en el exterior. En ocasiones, las políticas de prerrogativas o concesiones singularizadas a cada mercader por parte de los países hospedantes iban justo en dirección contraria: la de obstaculizar cualquier espíritu comunitario que condujera a la unión coagular entre connacionales. Además, más globalmente, recuérdese que los negociadores del Bajo Medievo operaban en un sistema comercial donde sobresalían las tendencias concurrentes y de competición continua, y donde los intereses individualizados de cada tratante o de cada empresa solían superarse sobre todo si determinadas agresiones económicas o políticas les obligaban a aliarse ${ }^{92}$.

91 APELLÁNIZ, F, "Collaboration des réseaux marchands à Alexandrie (XIVe-XV siècles), en RAMADA CURTO, D. y otros (eds.), From Florence to the Mediterranean and Beyond. Essays in Honour of Anthony Molho, Florencia, 2009, pp. 594 y 598.

92 PETTI BALBI, G., "Le nationes italiane ...", cit., p. 410; EADEM, "Il mercante", en Ceti, modelli, comportamenti nella società medievale (secoli XIII - metà XIV). Diciasette- 
Ante tales constataciones parece pertinente preguntarse, al examinar por doquier las presencias extranjeras, si en su interior imperaban los rasgos socioprofesionales de colaboración o competitividad, de solidaridad o atomización ${ }^{93}$. Es probable que la contestación a este interrogante facilitara la mejor comprensión de la trilogía de factores que, como se ha planteado desde la experiencia genovesa en la Castilla moderna, albergaba todo establecimiento foráneo de importancia: una "nación" o ascendencia común, diferentes familias y sujetos reunidos en su seno, múltiples redes de relación proyectadas dentro y fuera del grupo ${ }^{94}$.

En la Valencia del final de la Edad Media, la cuestión de los comerciantes extranjeros no ha sido abordada específicamente desde esta óptica. En hipótesis cabría creer que el balance del citado dualismo, entre colaboración/solidaridad y competitividad/atomización internas, entrelazaría en parte con el resultado de las lógicas de permeabilidad y de enfrentamiento hacia los autóctonos, expuestas previamente. Pero seguro que conecta de algún modo, a nivel causal y fenomenológico, con distintas variables en las que he venido insistiendo: la disparidad de las coyunturas, la dinámica de la política y las instituciones, la composición plural de los conjuntos de inmigrantes (con la posible división entre élites y personajes menores), y las funciones desplegadas por éstos en las áreas receptoras. Incluso, en este asunto como en otros, tuvo que jugar simultáneamente su papel la disociación por orígenes de los mercaderes foráneos. Y no sólo porque no todos los extranjeros reprodujeron unas mismas características en su expansión exterior y, en particular, en su asentamiento valenciano. También porque su actividad no tenía efectos reales similares, ni era juzgada igual por las autoridades y los operadores locales. En este sentido, basta apreciar en los siglos XIV y XV las actitudes a veces contrapuestas, por su expresión favorable o desfavorable, que mostraron los sectores dominantes urbanos en su acercamiento a los tráficos castellanos e italianos y, dentro de éstos últimos, a los protagonizados separadamente por toscanos, ligures, lombardos y vénetos ${ }^{95}$.

simo Convegno Internazionale di Studi (celebrado en Pistoia, 14-17 de mayo de 1999), Pistoia, 2001, p. 13.

93 GUIDI-BRUSCOLI, F., "The Network of Florentine Merchant-Banking Companies in the North of Europe: Collaboration vs Competition", comunicación 1121-c presentada a la sesión 1121 (Cities in Medieval Italy and Italians in Medieval Cities. V: Across the Great Divide - Merchants and Cities in Trans-alpine Trade), del International Medieval Congress (celebrado en Leeds, 9-12 de julio de 2007).

94 ALONSO GARCÍA, D., "Una nación, diferentes familias, múltiples redes. Genoveses en Castilla a principios de la Edad Moderna", en CRESPO SOLANA (coord.), Comunidades transnacionales ..., cit., pp. 65-82.

95 IGUAL LUIS, Valencia e Italia ..., cit., pássim; ÍDEM, "Política y economía ...", cit., pp. 265-267; ÍDEM, "Mercaderes castellanos y fiscalidad en Valencia (1487-1512)", en Homenaje a José Hinojosa Montalvo, Alicante, en prensa. 
En cualquier caso, con la suma de estas postreras variables al resto de las comentadas en el artículo, se completa un cuadro sobre los movimientos comerciales extranjeros en Valencia definido por su extraordinaria complejidad. A estas bases, el añadido de los numerosos horizontes que brinda el análisis detallado de cada mercader foráneo aún aporta mayores dosis de diversidad, por las circunstancias de todo tipo que provocaban el desplazamiento del individuo y los abundantes contextos, a veces enigmáticos para los historiadores, que justificaban sus decisiones y sus destinos. Precisamente, en un ejemplo parangonable de nuevo al valenciano, la combinación de este amplio abanico de elementos ha permitido diseñar a Maria Elisa Soldani los diferentes escenarios, entre la hospitalidad y el rechazo, con que los hombres de negocios de una misma procedencia (la toscana) fueron acogidos en la Barcelona del siglo XV. De forma parecida, pero refiriéndose ya a la Valencia cuatrocentista y observando a todos los mercaderes extranjeros de la ciudad, Enrique Cruselles ha resumido sus distintas condiciones a partir de los estatus jurídicos que disfrutaban y de los mecanismos sociales de los que participaban. Así habría que contar, por un lado, con la presencia coetánea aquí de operadores pertenecientes a comunidades enemigas, otros con cuyos gobiernos se habían acordado tratados o se mantenían relaciones políticas envidiables, y comerciantes que compraban salvoconductos reales o avecindamientos municipales. Mientras, interrelacionándose con estos criterios, por el otro debería considerarse a los agentes frente a quienes se mantenían las barreras de la exclusión y su identificación extranjera, y a los mercaderes que abandonaban las redes de su pasado alóctono para integrarse con pleno derecho en la sociedad local e intervenir en sus marcos de inserción ${ }^{96}$. Sin duda, para concluir, por debajo de las tendencias temporales, territoriales o grupales, también el extenso panorama de las trayectorias individuales faculta la ilustración, en la Valencia bajomedieval, de las cuantiosas perspectivas y ambivalencias que aglutina el tema del comercio y los extranjeros.

96 SOLDANI, Uomini d'affari ..., cit., p. 132; CRUSELLES GÓMEZ, Los mercaderes de Valencia ..., cit., pp. 60-61. 